\title{
Stability of steel beams using the continuous strength method
}

\author{
A. S. J. Fostera,*, L. Gardner ${ }^{\mathrm{b}}$ \\ ${ }^{a}$ University College London, London, UK \\ ${ }^{b}$ Imperial College London, London, UK
}

\begin{abstract}
Through a programme of experiments, numerical modelling and parametric studies, the implications of allowing for strain-hardening in the design of partially restrained steel beams is investigated. A total of fourteen tests were performed on simply supported beams that were partially restrained against lateral torsional buckling. Four different restraint spacings were considered in the tests to give non-dimensional lateral torsional slenderness values of $0.1,0.2,0.3$ and 0.4 for the unrestrained lengths. In all tests, bending resistances in excess of the plastic moment capacity were observed, but in order to attain the levels of resistance predicted by the continuous strength method (CSM), which allows for strainhardening, closer restraint spacing than the minimum specified by EN 1993-1-1 (2005) is required. Using additional data generated as part of an analytical and numerical study, as well as test data collected from the literature, a basic design approach was presented that incorporated a limiting lateral torsional slenderness for the CSM of 0.2, as well as a simple transition function from bending resistances predicted by plastic theory to those predicted by the CSM.
\end{abstract}

\section{Introduction}

Lateral stability of beams is a key aspect of structural steel design. For beams designed in the inelastic range, the current practice in European design codes is to specify a maximum lateral torsional buckling slenderness $\bar{\lambda}_{\mathrm{LT}}$ below which the effects of lateral instability can

\footnotetext{
${ }^{*}$ Corresponding author

Email address: ucesasj@ucl.ac.uk (A. S. J. Foster)
} 
be ignored and the full cross-section capacity can be achieved; beyond this limit, reductions in capacity arise.

Currently, inelastic design of structures according to EN 1993-1-1 assumes an elasticperfectly plastic (EPP) stress-strain curve, and a limiting value of $\bar{\lambda}_{\mathrm{LT}}=0.4$, below which the effects of lateral torsional buckling can be ignored. In a newly proposed design method, referred to herein as the Continuous Strength Method (CSM) [1], strain-hardening is allowed for in the material model, with the limiting strain defined as a function of local plate slenderness $\bar{\lambda}_{\mathrm{p}}$. This research is devoted to examining the implications of this new method for the limiting value of $\bar{\lambda}_{\mathrm{LT}}$. To this end, the data from a series of experiments on simply supported beams with variations in $\bar{\lambda}_{\mathrm{LT}}$ was used in conjunction with data collected from the literature. Using a geometrically and materially non-linear finite element model, the test data were reproduced and extended in a parametric study, which was then used to inform and support analytically derived design equations.

\section{Key design aspects}

\subsection{Lateral restraint spacing}

EN 1993-1-1 (2005) defines a non-dimensional slenderness limit, or plateau length, $\bar{\lambda}_{\mathrm{LT}}=$ 0.4, below which, the effects of lateral torsional buckling can be ignored and the design buckling resistance moment of the member $M_{\mathrm{b}, \mathrm{Rd}}$ may be taken as as the design bending resistance $M_{\mathrm{c}, \mathrm{Rd}}$ of the cross-section, assuming $\gamma_{\mathrm{M} 0}=\gamma_{\mathrm{M} 1} \cdot \bar{\lambda}_{\mathrm{LT}}$ is defined in Eq. (1) as:

$$
\bar{\lambda}_{\mathrm{LT}}=\sqrt{\frac{W_{\mathrm{y}} f_{\mathrm{y}}}{M_{\mathrm{cr}}}}
$$

in which $W_{\mathrm{y}}$ is the major axis plastic section modulus for Class 1 and 2 cross-sections, the elastic section modulus for Class 3 cross-sections and an effective section modulus for Class 4 cross-sections, $f_{\mathrm{y}}$ is the material yield strength and $M_{\mathrm{cr}}$ is the elastic critical moment for lateral torsional buckling, which is a function of member length $L$. For a given set of 
cross-section and material properties and a fixed value of $\bar{\lambda}_{\mathrm{LT}}$, Eq. (1) can be solved for $L$ to define the maximum allowable spacing between fully effective lateral restraints before reductions in resistance for lateral torsional buckling are required. For members containing plastic hinges, stable lengths below which lateral torsional buckling can be ignored are given in Annex BB-1 of EN-1993-1-1 (2005).

\subsection{The continuous strength method (CSM)}

The continuous strength method is a deformation-based design approach for steel elements that allows for the beneficial influence of strain-hardening. To date, design equations for the CSM have been developed for cross-section resistance in bending and compression [2]. The CSM bending resistance function $M_{\mathrm{csm}, \mathrm{Rd}}$, which applies for $\bar{\lambda}_{\mathrm{p}} \leq 0.68$ is defined in Eq. (2) as:

$$
M_{\mathrm{csm}, \mathrm{Rd}}=\frac{W_{\mathrm{pl}} f_{\mathrm{y}}}{\gamma_{\mathrm{M} 0}}\left(1+\frac{E_{\mathrm{sh}}}{E} \frac{W_{\mathrm{el}}}{W_{\mathrm{pl}}}\left(\frac{\epsilon_{\mathrm{csm}}}{\epsilon_{\mathrm{y}}}-1\right)-\left(1-\frac{W_{\mathrm{el}}}{W_{\mathrm{pl}}}\right)\left(\frac{\epsilon_{\mathrm{csm}}}{\epsilon_{\mathrm{y}}}\right)^{-2}\right)
$$

where $E$ is the modulus of elasticity, $E_{\mathrm{sh}}$ is the strain-hardening slope taken equal to $E / 100$ for structural steel, $W_{\mathrm{el}}$ and $W_{\mathrm{pl}}$ are the elastic and plastic section moduli and $\epsilon_{\mathrm{csm}} / \epsilon_{\mathrm{y}}$ is the strain ratio, defining the limiting strain in the cross-section as a multiple of the yield strain $\epsilon_{\mathrm{y}}$, and given by Eq. (3):

$$
\frac{\epsilon_{\mathrm{csm}}}{\epsilon_{\mathrm{y}}}=\frac{0.25}{\bar{\lambda}_{\mathrm{p}}^{3.6}} \text { but } \leq 15
$$

in which $\bar{\lambda}_{\mathrm{p}}$ is the local cross-section slenderness, given by Eq. (4) as:

$$
\bar{\lambda}_{\mathrm{p}}=\sqrt{\left(f_{\mathrm{y}} / \sigma_{\mathrm{cr}}\right)}
$$

with $\sigma_{\mathrm{cr}}$ being the elastic buckling stress of the cross-section, or conservatively its most slender constituent plate element. 
This study will examine the implications of using the CSM resistance function where moments beyond $M_{\mathrm{pl}, \mathrm{Rd}}$ can be sustained on the limiting lateral torsional slenderness below which the effects of lateral torsional buckling can be ignored, following a series of experiments, numerical simulations and analytical models.

\section{Experimental programme}

\subsection{Introduction}

A testing programme comprising tensile and compressive material coupon tests, stub column tests and tests on beams with discrete lateral restraints was carried out at the Building Research Establishment and Imperial College London on hot-rolled grade S355 steel I-sections. Two cross-section sizes were chosen: $305 \times 127 \times 48$ UB, which had a Class 1 flange $\left(\bar{\lambda}_{\mathrm{p}}=0.31\right)$ and a Class 1 web $\left(\bar{\lambda}_{\mathrm{p}}=0.30\right)$, and $305 \times 165 \times 40 \mathrm{UB}$, which had a Class 2 flange $\left(\bar{\lambda}_{\mathrm{p}}=0.57\right)$ and a Class 1 web $\left(\bar{\lambda}_{\mathrm{p}}=0.44\right)$. In addition, supplementary data from tests on partially restrained beams were sourced from the literature.

\subsection{Material properties}

Tensile and compressive coupon tests were used to determine the engineering stress-strain material response of the tested specimens; the tests were conducted in the Structures Laboratory of the Department of Civil and Environmental Engineering, Imperial College London.

Tensile and compressive coupons were cut and milled from the web and flanges of two representative UB sections in the longitudinal (rolling) direction only. Testing was carried out in accordance with the provisions of EN 10002-1 (2001). The nominal dimensions of the necked tensile coupons were $320 \times 30 \mathrm{~mm}$ and the nominal dimensions of the compressive coupons were $72 \times 16 \mathrm{~mm}$. Prior to testing, half gauge lengths were marked onto the tensile coupons to allow the final strain at fracture, $\epsilon_{\mathrm{f}}$, to be calculated, based on elongation over the standard gauge length $5.65 \sqrt{A_{\mathrm{c}}}$ where $A_{\mathrm{c}}$ is the cross-sectional area of the coupon. The tensile coupon tests were carried out in an INSTRON $500 \mathrm{kN}$ hydraulic loading machine with an initial strain rate of $0.001 \% / \mathrm{s}$ for $\epsilon<0.5 \%$. Between $0.5 \%$ and $4 \%$ strain, the 
strain rate was $0.002 \% / \mathrm{s}$; between $4 \%$ and $17 \%$ strain, the strain rate was $0.04 \% / \mathrm{s}$. Once the coupon reached $\epsilon=17 \%$ testing switched to displacement control at a constant rate of $0.1 \mathrm{~mm} / \mathrm{s}$ until failure. Static yield and ultimate strengths were determined by holding the strain constant for two minutes in the yield plateau and at four points near the ultimate stress. Tensile strain was measured using clip gauge and video extensometers.

Compressive coupons were placed in a restraining jig to prevent buckling (Fig. 1) and were machined flat to ensure they were in a state of pure compression. Tests were carried out in an INSTRON $500 \mathrm{kN}$ hydraulic loading machine and strain measurements were obtained from strain gauges bonded to the sides of the samples at mid-height. Testing was carried out using displacement control at a constant rate of $0.067 \mathrm{~mm} / \mathrm{min}$ until the protruding end of the coupon was almost flush with the testing jig.

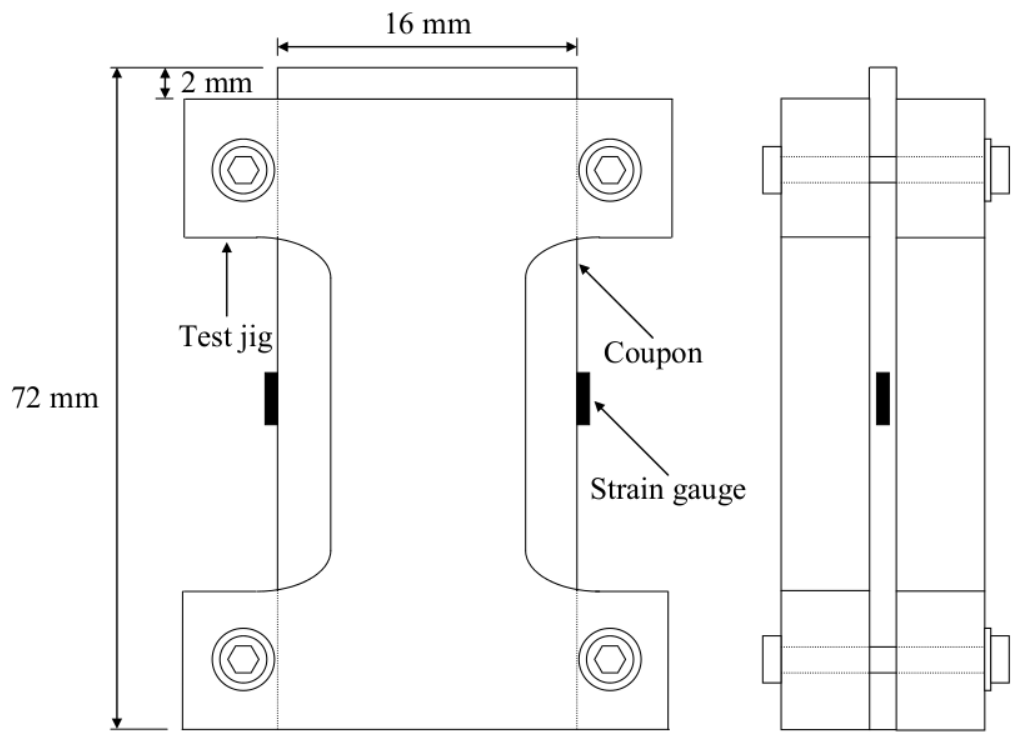

Figure 1: Compressive coupon testing jig and nominal coupon dimensions.

All test data, including load, displacement, strain and input voltage were recorded at one-second intervals using the DATASCAN acquisition system. A summary of the results of these tests is provided in Table 1. In the coupon designation, T denotes a tensile test, C 
denotes a compressive test, $\mathrm{W}$ denotes a coupon taken from the web and $\mathrm{F}$ denotes a coupon taken from the flange. Other symbols are defined as follows: $b_{c}$ is coupon width, $t_{c}$ is coupon thickness, $A$ is cross-sectional area, $E$ is the modulus of elasticity, $f_{\mathrm{y}}$ is the material yield strength, $f_{\mathrm{u}}$ is the ultimate tensile strength, $\epsilon_{\mathrm{f}}$ is the strain at fracture calculated over the standard gauge length set out in EN 10002-1 (2001), and $\epsilon_{\mathrm{u}}$ is the strain at the ultimate tensile stress. The stress-strain curves for the tensile and compressive coupons are shown in Figs 2-5.

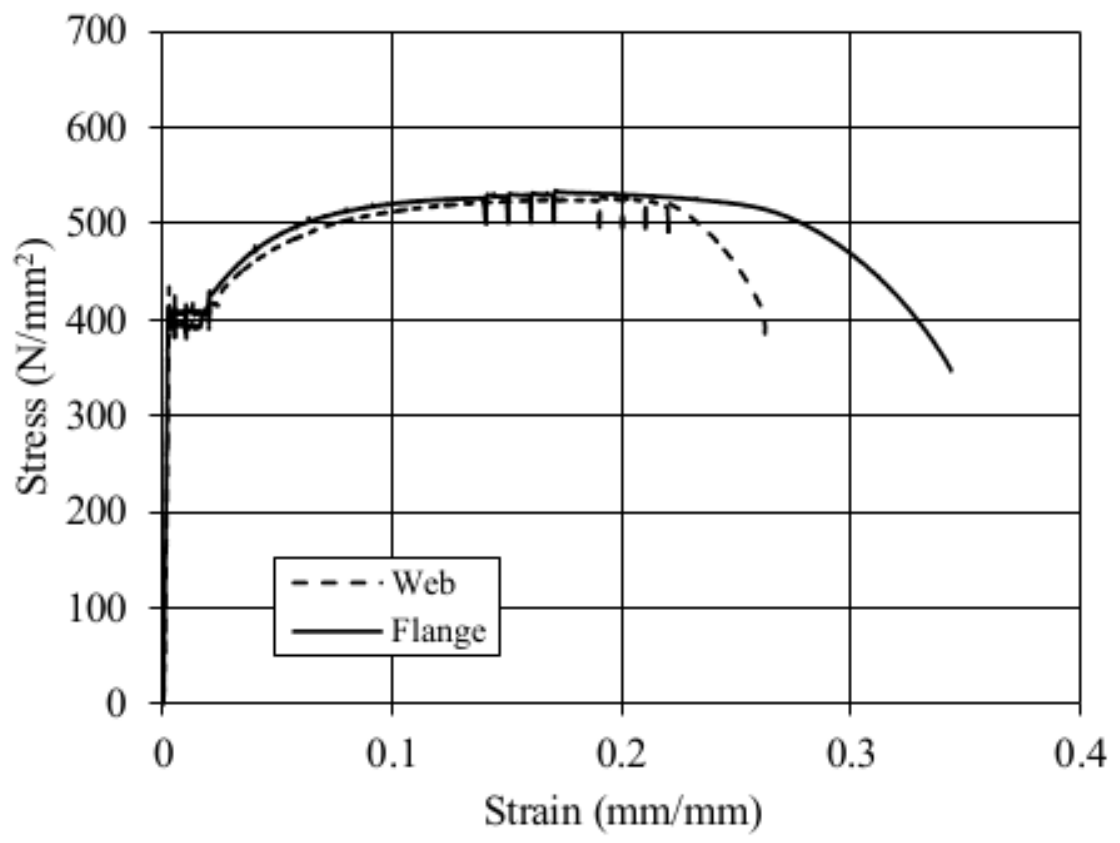

Figure 2: Full tensile stress-strain curves for the flange and web of the $305 \times 127 \times 48$ UB section.

The tensile and compressive coupons exhibited the anticipated response of a well defined yield point, followed by a plateau before the initiation of strain-hardening. For the compressive coupons, due to the need to prevent buckling, there is a limited amount of material available for deformation; thus, the curves presented in Figs. 4 and 5 do not present the entire compressive stress-strain response. However, like the tensile coupons, there is a defined yield point followed by a plateau prior to the onset of strain-hardening. 


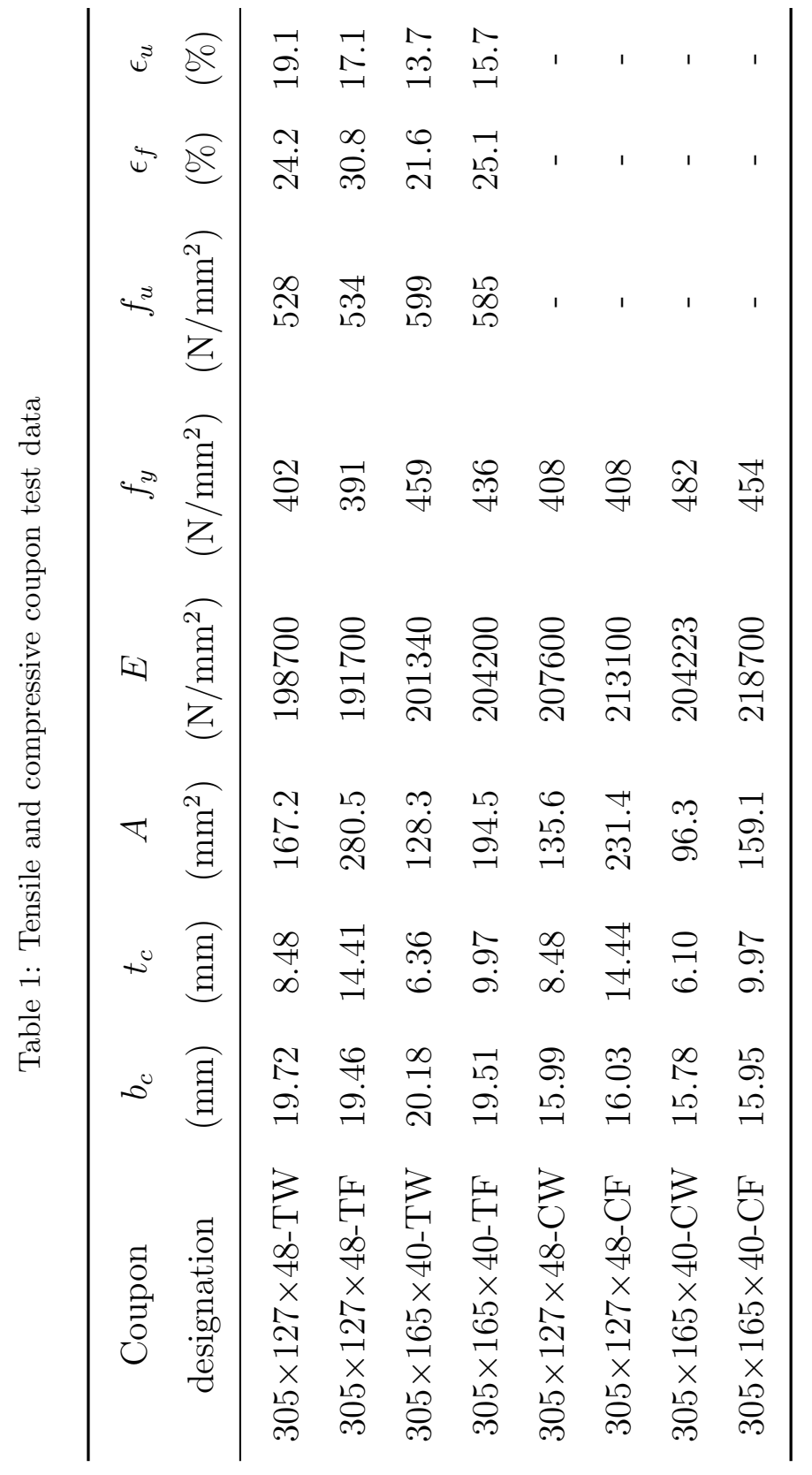




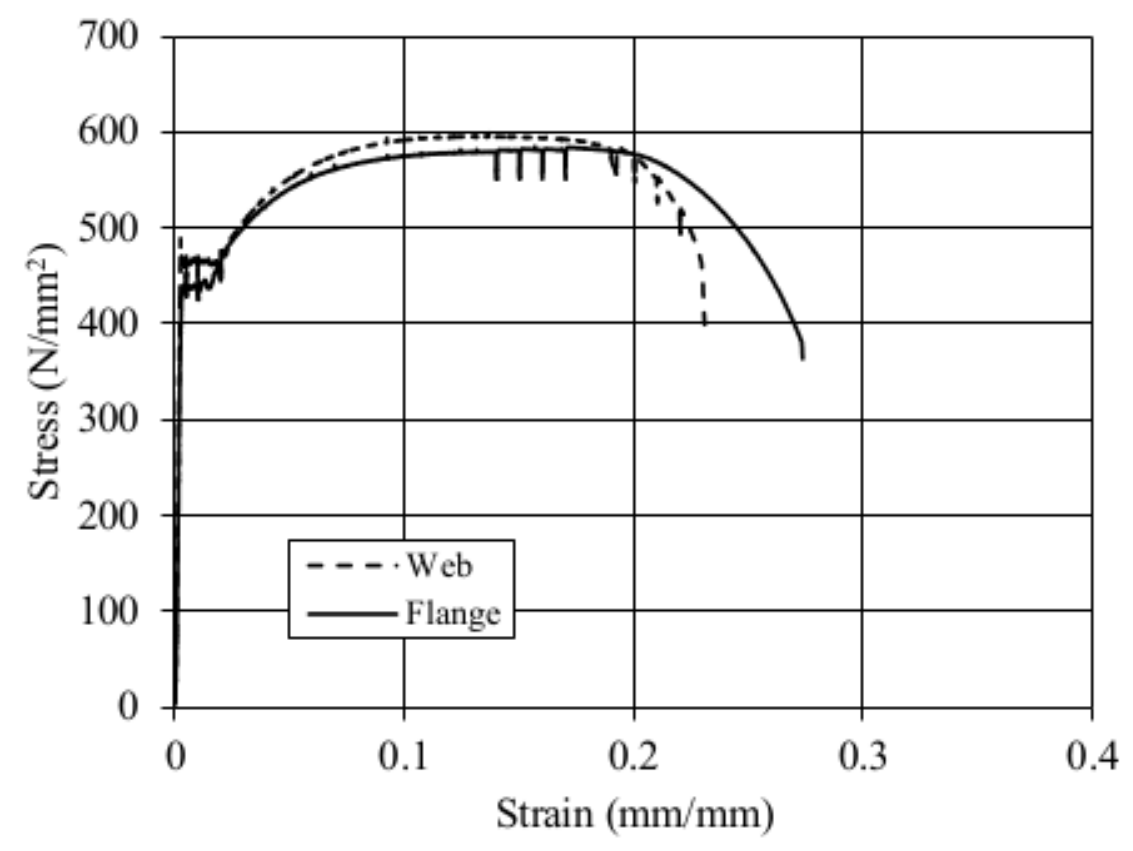

Figure 3: Full tensile stress-strain curves for the flange and web of the $305 \times 165 \times 40$ UB section.

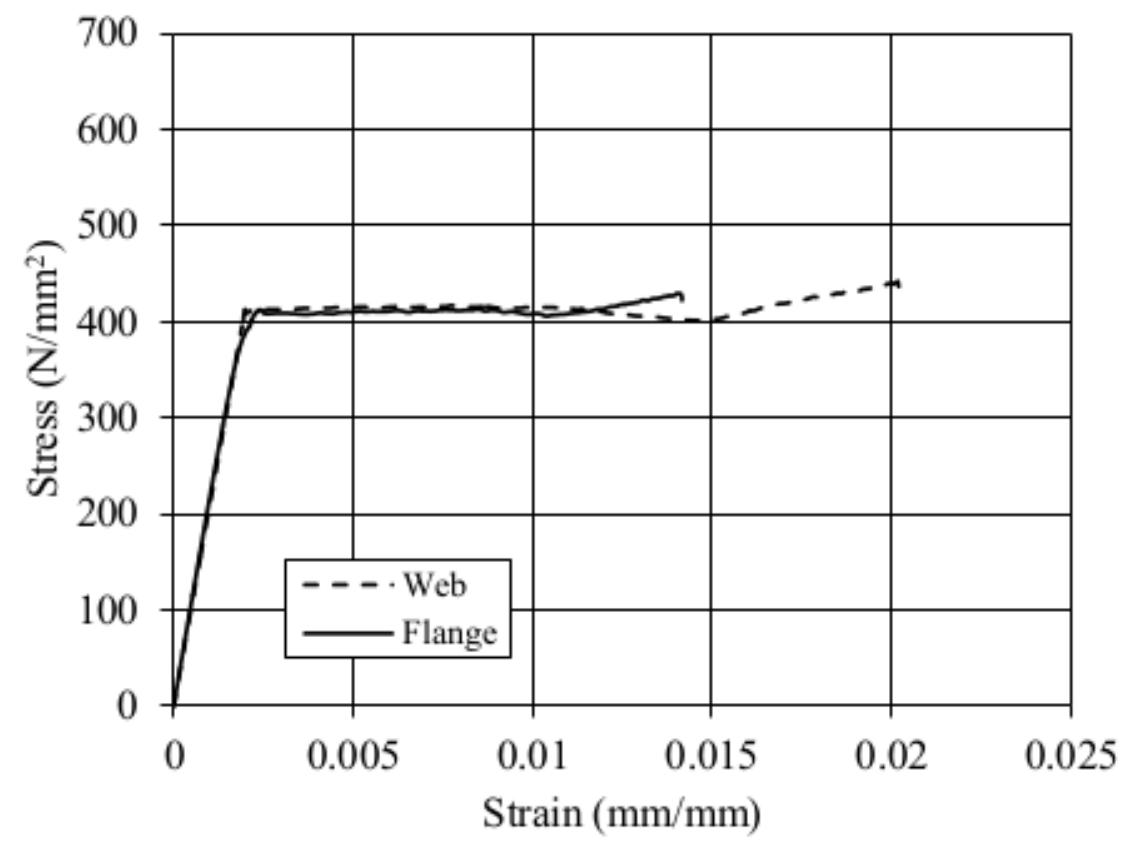

Figure 4: Initial portion of the compressive stress-strain curves for the flange and web of the $305 \times 127 \times 48$ UB section. 


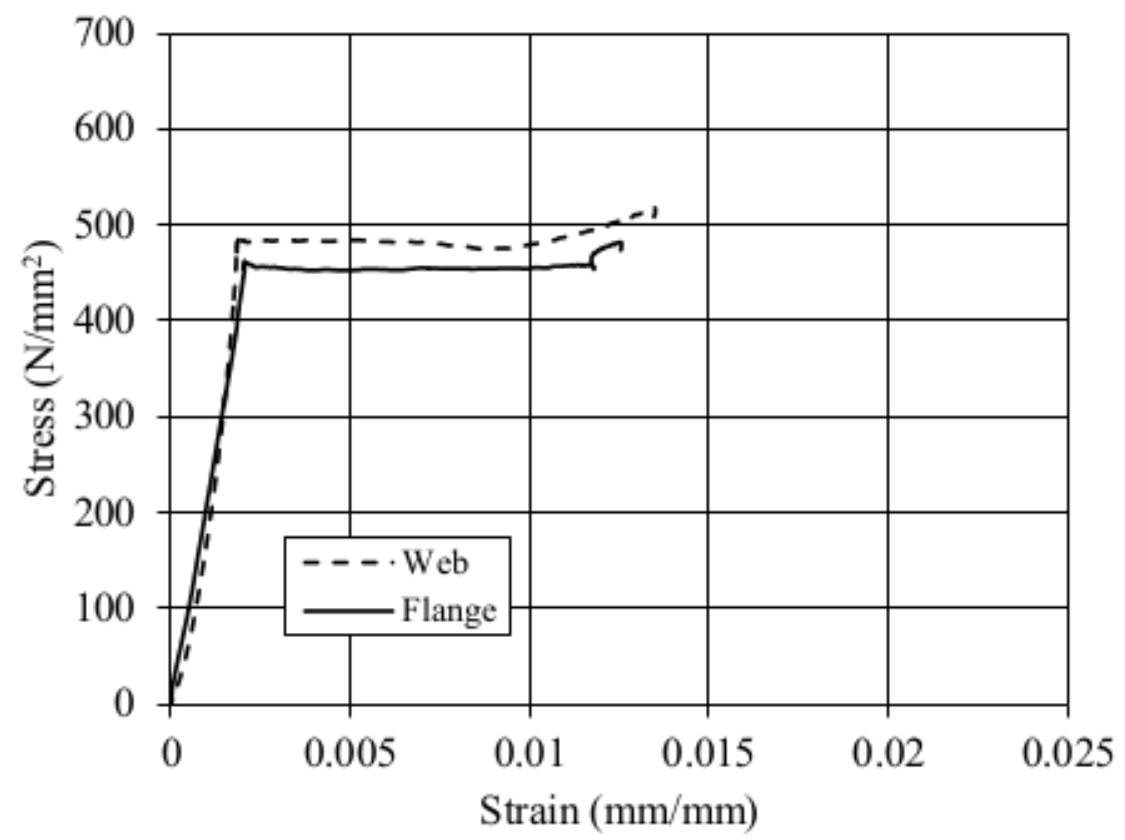

Figure 5: Initial portion of the compressive stress-strain curves for the flange and web of the $305 \times 165 \times 40$ UB section.

\subsection{Stub column tests}

Compressive stub column tests were performed to investigate the average compressive response of the cross-sections, including the influence of local buckling. The nominal length of the stub columns was selected as twice the overall height of the cross-section but with a global slenderness, $\bar{\lambda}_{z}=\left(A f_{\mathrm{y}} / N_{\mathrm{cr}}\right)^{1 / 2}$ where $N_{\mathrm{cr}}$ is the elastic buckling load, not greater than 0.1. This ensures that overall buckling does not occur, but sufficient length remains to include a representative distribution of local geometric imperfections and residual stresses. The ends of the specimens were machined flat and true to ensure uniform contact with the end platens of the testing machine.

Displacements were recorded by two LVDTs in contact with the end platens, the applied load was recorded with a load cell, and four strain gauges attached at the mid-height of the flanges and web were used to ensure concentric load application as well as to eliminate elastic end platen deformations from the end shortening data. Testing was carried out in an 
INSTRON $3500 \mathrm{kN}$ universal testing machine under displacement-control at a rate of 0.067 $\mathrm{mm} / \mathrm{min}$. Results, including load, displacements, strain and input voltage were recorded at one-second intervals using the data acquisition system DATASCAN. Testing was continued beyond the ultimate load-carrying capacity of the stub columns to examine the post-ultimate response. The stub column geometric properties and key test results are presented in Table 2. For each section used, SC1 denotes the first stub column test and SC2 denotes the second stub column test, $h$ is the overall section height, $b$ is the overall section width, $t_{f}$ is the flange thickness, $t_{w}$ is the web thickness, $L_{s c}$ is the stub column length, and $N_{\mathrm{u}}$ is the ultimate test load.

Table 2: Stub column test data

\begin{tabular}{ccccccc}
\hline $\begin{array}{c}\text { Stub column } \\
\text { designation }\end{array}$ & $\begin{array}{c}t_{f} \\
(\mathrm{~mm})\end{array}$ & $\begin{array}{c}t_{w} \\
(\mathrm{~mm})\end{array}$ & $\begin{array}{c}h \\
(\mathrm{~mm})\end{array}$ & $\begin{array}{c}b \\
(\mathrm{~mm})\end{array}$ & $\begin{array}{c}L_{s c} \\
(\mathrm{~mm})\end{array}$ & $\begin{array}{c}N_{u} \\
(\mathrm{kN})\end{array}$ \\
\hline $305 \times 127 \times 48-\mathrm{SC} 1$ & 13.93 & 8.59 & 311.21 & 127.54 & 622 & 2487 \\
$305 \times 127 \times 48-\mathrm{SC} 2$ & 13.95 & 8.87 & 311.56 & 127.82 & 622 & 2487 \\
$305 \times 165 \times 40-\mathrm{SC} 1$ & 9.80 & 6.11 & 306.53 & 166.87 & 607 & 2124 \\
$305 \times 165 \times 40-\mathrm{SC} 2$ & 9.78 & 6.05 & 305.49 & 166.52 & 607 & 2192 \\
\hline
\end{tabular}

All specimens failed by local buckling and examples of each cross-section can be seen in Fig. 6. Using load, displacement and strain data obtained from the test, load-true end shortening curves are plotted in Fig. 7. During the test, the end platens undergo small elastic deformations that can overstate the displacement readings from the LVDTs. In a procedure developed by C.A.S.E. [3] the recorded LVDT displacements, $\delta_{\mathrm{LVDT}}$, can be modified to obtain true end shortening, $\delta_{\mathrm{ES}}$, where:

$$
\delta_{\mathrm{ES}}=\delta_{\mathrm{LVDT}}-2 \Delta_{\mathrm{platen}}
$$

Defining $E_{0, \mathrm{LVDT}}$ as the elastic modulus relating stress, $\sigma$, to LVDT strain and $E_{0, \text { true }}$ as the 
elastic modulus relating stress to strain gauge strains, the the deformation of the platens, $\Delta_{\text {platen}}$, can be calculated using Eq. (6):

$$
\Delta_{\text {platen }}=\frac{L_{s c}}{2} \sigma\left(\frac{1}{E_{0, \mathrm{LVDT}}}-\frac{1}{E_{0, \text { true }}}\right)
$$

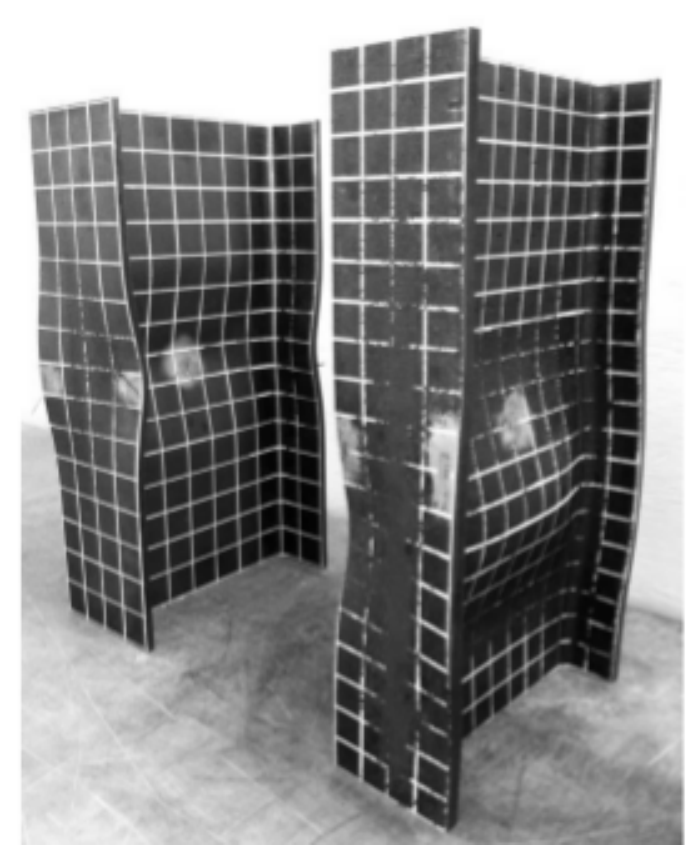

Figure 6: Test specimens showing typical stub column mode of failure.

\subsection{Measurement of geometric imperfections}

A total of twelve beam tests were carried out. For each experiment, the basic geometry of the test specimen was measured prior to testing. Global imperfection amplitude measurements were taken for each specimen by holding a fine copper wire at mid-web height taught along the length of the beam and then measuring the distance between the wire and the beam at the mid-length. Local imperfections were measured by placing a representative sample of each section on the bed of a milling machine with an LVDT held securely in the head of the machine. With the LVDT positioned on either the centreline of the web or the tip of the outstand flanges, the specimen was passed up and down and the profile of its 


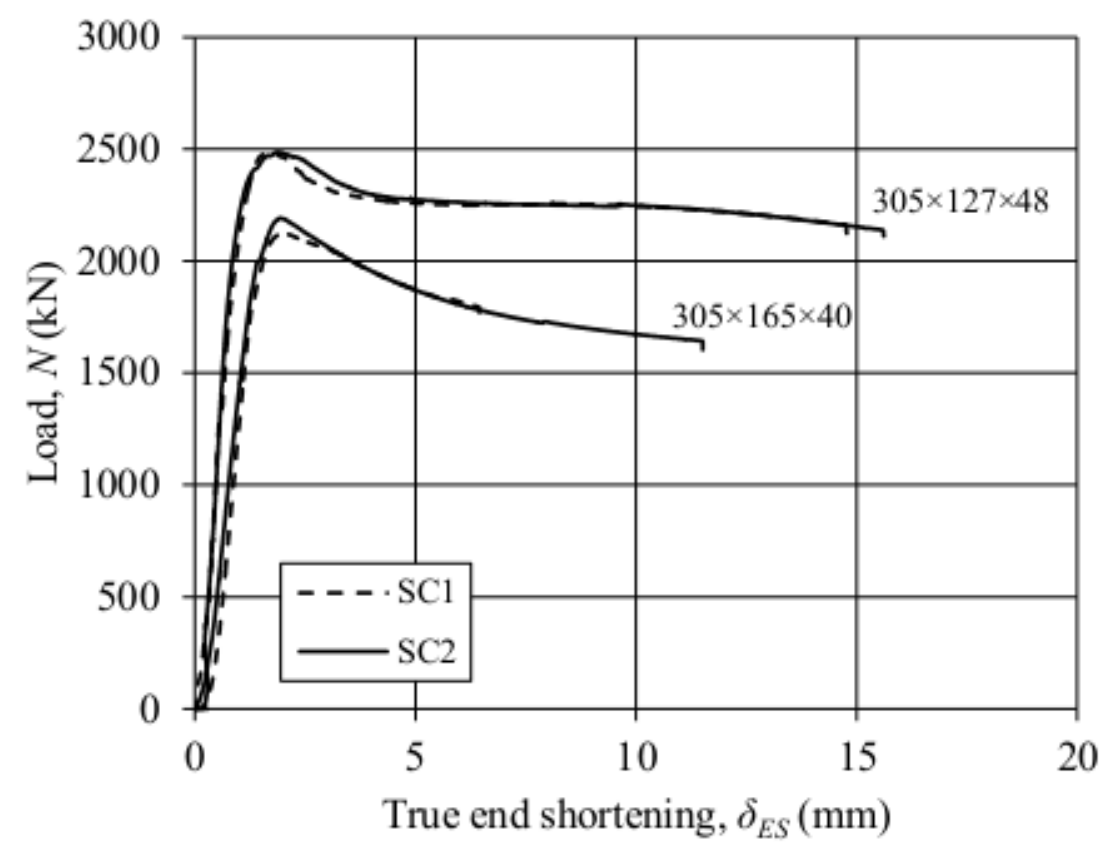

Figure 7: Stub columns load-true end shortening curves.

surface was recorded. The maximum deviation from a straight line connecting the ends of the measured length was taken as the local imperfection magnitude. The basic geometric measurements, global imperfection magnitudes, and local flange imperfection magnitudes are reported in Table 3 .

\subsection{Tests on beams with discrete elastic lateral restraints}

A total of twelve four-point and two three-point bending tests were conducted. Fig. 8 shows the general test configurations for the four-point and three-point bending tests.

For all tests, rigid lateral restraints were provided at the loading points and at the supports. For the four-point bending tests, the length $L_{2}$ was varied to achieve desired values of $\bar{\lambda}_{\mathrm{LT}}$ for each test; $L_{1}$ was chosen in relation to $L_{2}$ to ensure that buckling takes place in the $L_{2}$ region first. Two values of $\bar{\lambda}_{\mathrm{LT}}$ were investigated in the four-point bending tests - 0.3 and 0.4. In the three-point bending tests, the rigid lateral restraints were placed at intervals 


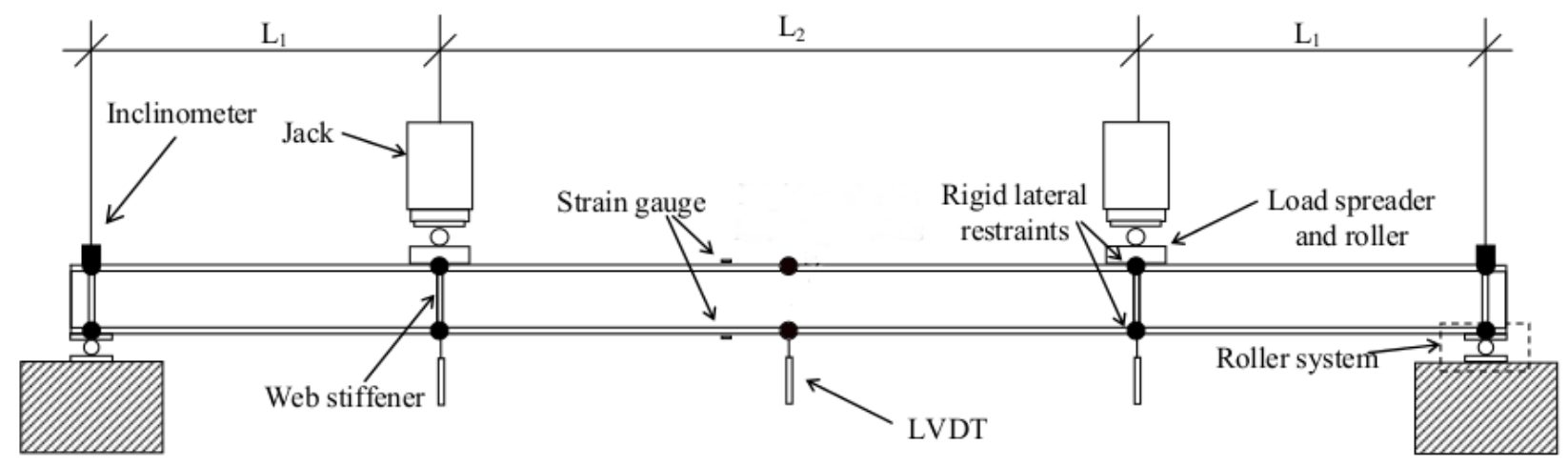

(a) Schematic illustration of the four-point bending test configuration.

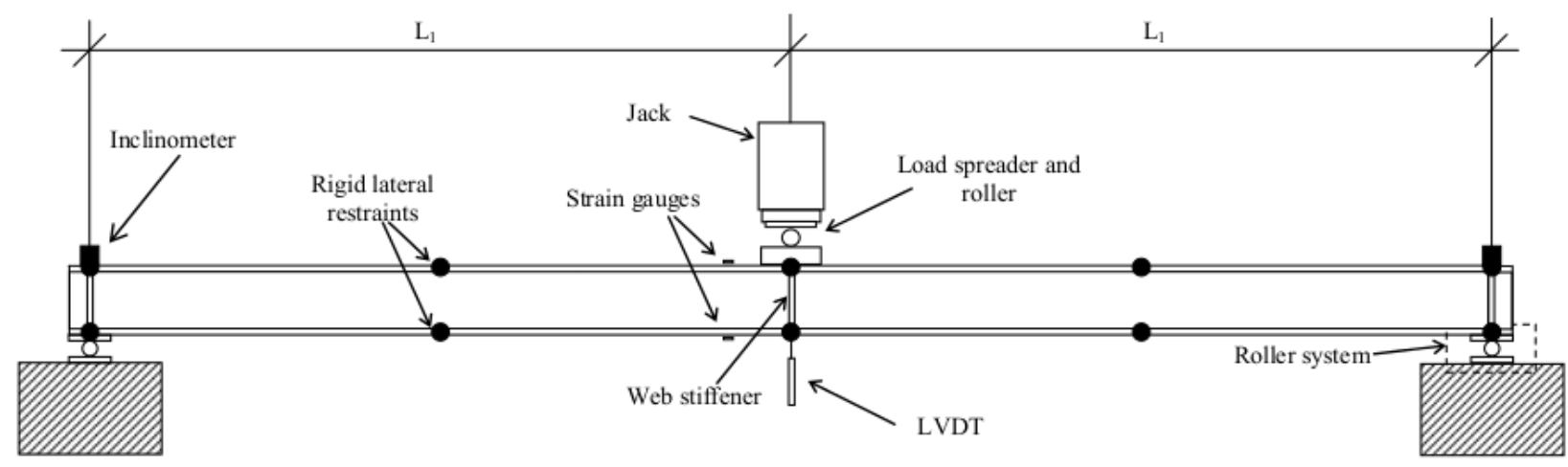

(b) Schematic illustration of the three-point bending test configuration.

Figure 8: Schematic illustrations of bending tests.

such that $\bar{\lambda}_{\mathrm{LT}}=0.1$ and 0.2 ; these tests were included to attain more pronounced strain hardening behaviour than was possible with the four-point tests, as well as to examine the effect of having closer restraint spacing.

For each test, web stiffeners were provided at the positions of the supports and the applied loads to prevent premature failure through web crippling. Vertical displacements were measured using pull-wire transducers and end rotations were measured using inclinometers; force was applied at each loading point using two hand operated $250 \mathrm{kN}$ load-controlled hydraulic jacks and forces were monitored with load cells. Two linear electrical resistance post-yield strain gauges were bonded to the extreme tensile and compressive fibres of the cross-section 


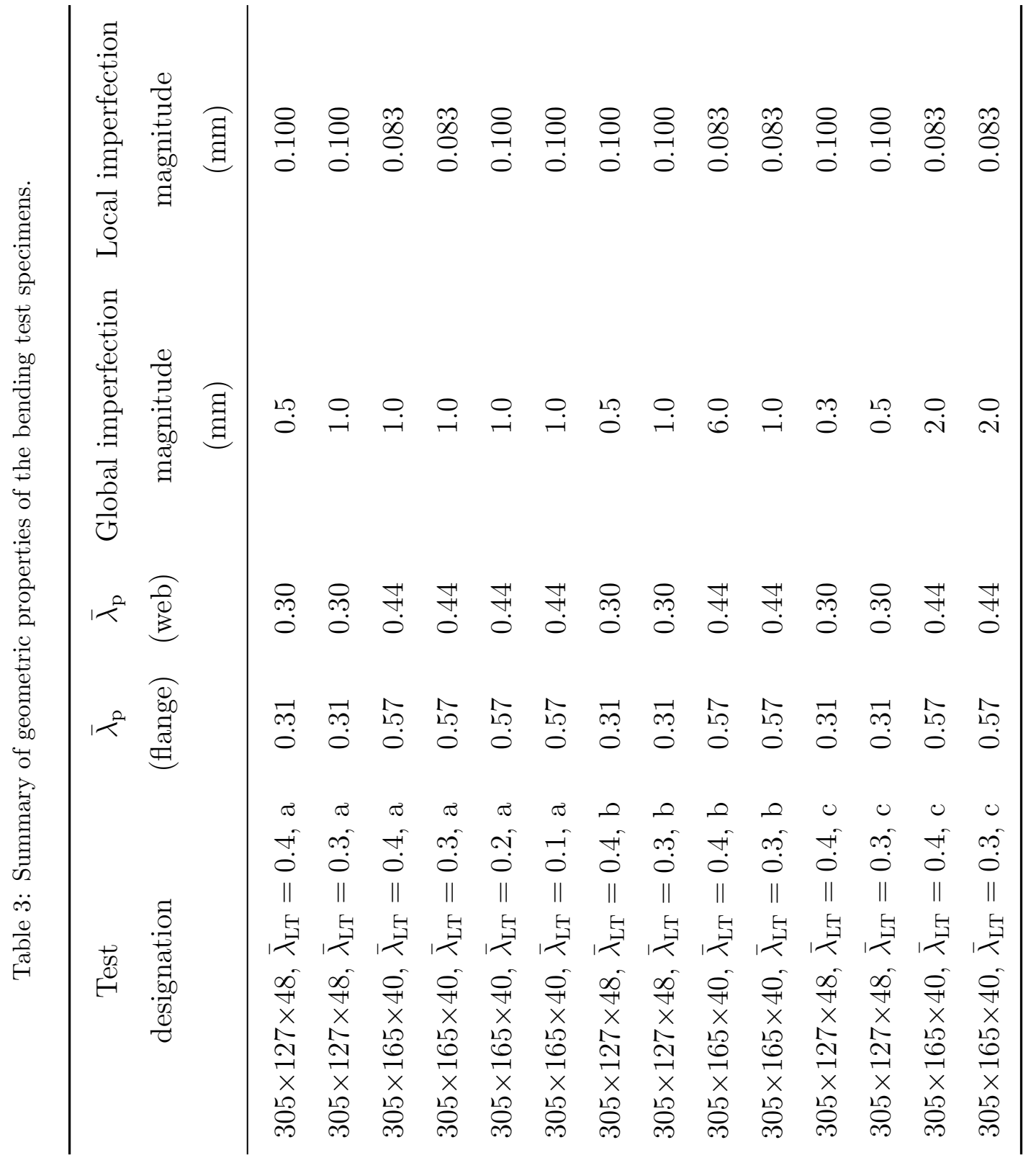


at the mid-span (or off-set where necessary). Simple support conditions were provided by a roller system, with longitudinal movement permitted at one end using a sliding plate system. Loads, rotations, displacements and strains were all recorded at one-second intervals using the data acquisition system DATASCAN. The key test results are presented in Table 4.

Table 4: Key test results for the three-point bending tests.

\begin{tabular}{lccc}
\hline Test & $M_{u}$ & $M_{u} / M_{\mathrm{csm}, \mathrm{Rd}}$ & $M_{u} / M_{\mathrm{pl}, \mathrm{Rd}}$ \\
designation & $(\mathrm{kNm})$ & & \\
\hline $305 \times 127 \times 48, \bar{\lambda}_{\mathrm{LT}}=0.4, \mathrm{a}$ & 286.8 & 0.93 & 1.04 \\
$305 \times 127 \times 48, \bar{\lambda}_{\mathrm{LT}}=0.3, \mathrm{a}$ & 291.1 & 0.94 & 1.05 \\
$305 \times 165 \times 40, \bar{\lambda}_{\mathrm{LT}}=0.4, \mathrm{a}$ & 280.2 & 1.03 & 1.02 \\
$305 \times 165 \times 40, \bar{\lambda}_{\mathrm{LT}}=0.3, \mathrm{a}$ & 281.5 & 1.03 & 1.03 \\
$305 \times 127 \times 48, \bar{\lambda}_{\mathrm{LT}}=0.2, \mathrm{a}$ & 318.1 & 1.02 & 1.15 \\
$305 \times 127 \times 48, \bar{\lambda}_{\mathrm{LT}}=0.1, \mathrm{a}$ & 334.2 & 1.07 & 1.21 \\
$305 \times 127 \times 48, \bar{\lambda}_{\mathrm{LT}}=0.4, \mathrm{~b}$ & 283.2 & 0.91 & 1.03 \\
$305 \times 127 \times 48, \bar{\lambda}_{\mathrm{LT}}=0.3, \mathrm{~b}$ & 298.6 & 0.96 & 1.08 \\
$305 \times 165 \times 40, \bar{\lambda}_{\mathrm{LT}}=0.4, \mathrm{~b}$ & 274.6 & 1.01 & 1.00 \\
$305 \times 165 \times 40, \bar{\lambda}_{\mathrm{LT}}=0.3, \mathrm{~b}$ & 293.0 & 1.07 & 1.07 \\
$305 \times 127 \times 48, \bar{\lambda}_{\mathrm{LT}}=0.4, \mathrm{c}$ & 289.1 & 0.93 & 1.05 \\
$305 \times 127 \times 48, \bar{\lambda}_{\mathrm{LT}}=0.3, \mathrm{c}$ & 294.7 & 0.95 & 1.07 \\
$305 \times 165 \times 40, \bar{\lambda}_{\mathrm{LT}}=0.4, \mathrm{c}$ & 279.0 & 1.02 & 1.02 \\
$305 \times 165 \times 40, \bar{\lambda}_{\mathrm{LT}}=0.3, \mathrm{c}$ & 279.9 & 1.02 & 1.02 \\
\hline
\end{tabular}

\subsection{Test results collected from the literature}

Additional experimental data have been collected from tests conducted on I-beams with either continuous or discrete (partial) lateral restraints. The majority of the existing data is in the lateral torsional slenderness range of $\bar{\lambda}_{\mathrm{LT}} \geq 0.4$, with a small number of studies 
investigating behaviour in the range $0 \leq \bar{\lambda}_{\mathrm{LT}} \leq 0.4$.

The majority of the collected data comes from a previous survey carried out by [4], which was used to compare numerically derived lateral torsional buckling curves with data taken from tests on rolled and welded I-sections; these data are denoted as ECCS (rolled) and ECCS (welded) respectively. Tests by [5] were conducted to investigate the bending strength enhancements over $M_{\mathrm{pl}}$ due to strain-hardening of partially and fully laterally restrained Isections, with $\bar{\lambda}_{\mathrm{LT}}=0.4$ and 0 . For values of $\bar{\lambda}_{\mathrm{LT}} \leq 0.4$, test data were obtained from a series of experiments [6-8] carried out at Lehigh University between 1956 and 1963. Nondimensional ultimate moments, with respect to $M_{\mathrm{pl}}$, and corresponding lateral torsional slenderness values from these tests, as well as results from the tests described in Section 3, are summarised in Fig. 9. The results indicate that the current limit to the Eurocode 3 plateau length of $\bar{\lambda}_{\mathrm{LT}}=0.4$ is suitable, since below this limit capacities of at least $M_{\mathrm{pl}}$ are typically achieved. These experimental data, supplemented with further numerical results generated in Section 4, will be used to assess a suitable limiting slenderness when considering strain-hardening. All of the considered cross-sections from the above sources were either Class 1 or Class 2. 


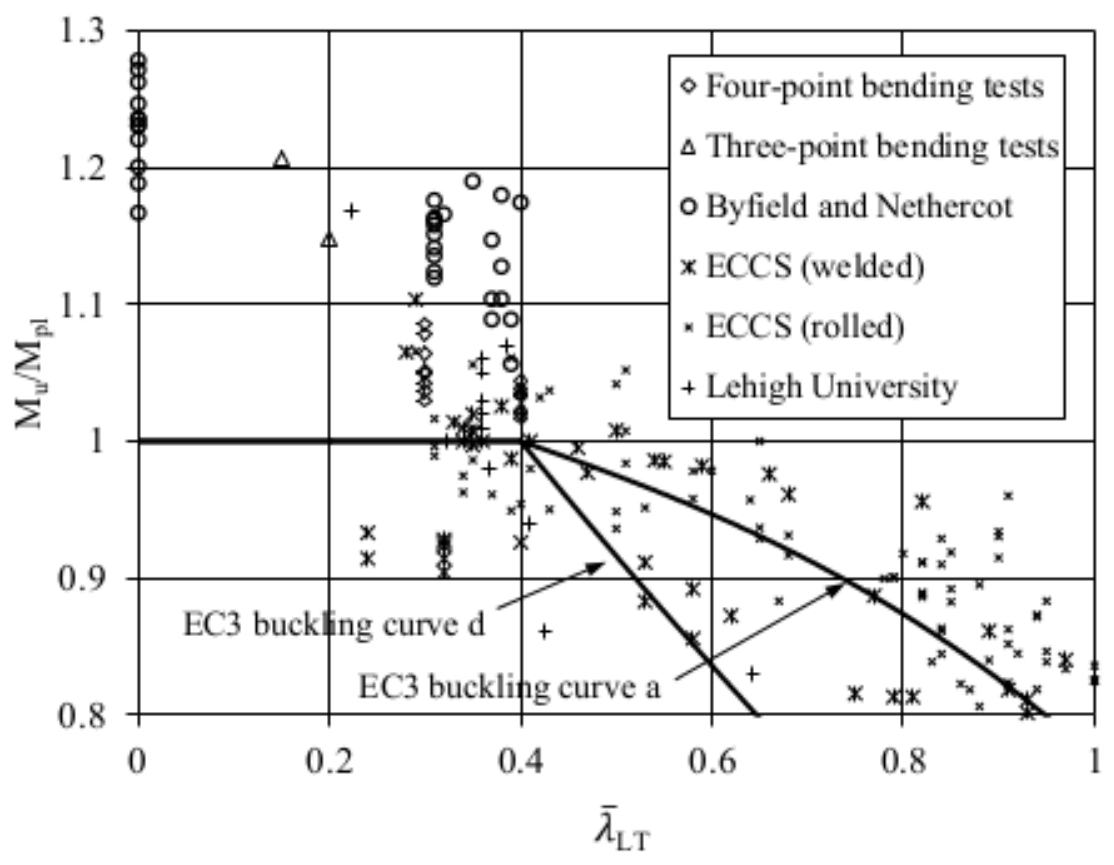

Figure 9: Summary non-dimensional ultimate moment capacities versus lateral torsional buckling slenderness for experimental data taken from the literature and produced in this study

\section{Numerical modelling}

\subsection{Introduction}

A numerical study using the general-purpose finite element analysis package ABAQUS [9] was conducted in parallel with the testing programme. The primary aims of the investigation were to (1) replicate the experimental results using all available measurements, (2) employ a standardised numerical model validated against the experimental data, and (3) undertake parametric studies to determine the minimum spacing requirements to achieve the predicted CSM capacity in bending.

\subsection{Basic modelling assumptions}

The finite element type S4R, a four-noded, doubly curved general-purpose shell element with reduced integration and finite membrane strains, selected from the ABAQUS [9] element library, was used throughout the study to model the beams. This element is suited to the modelling of a range of shell thicknesses and has been successfully implemented in other 
studies, such as Chan and Gardner [10].

To replicate the results from the experimental programme, measured geometric and material properties obtained prior to testing were incorporated into the finite-element models; for the standardised model, measured local and global geometric imperfection magnitudes were replaced with assumed values. Boundary conditions were applied to model simple support conditions at the ends and lateral displacements were constrained at the locations of the rigid restraints; longitudinal displacements were prevented at the mid-spans of the beams. The combined effects of material and geometric non-linearity were allowed for, with the modified Riks (arc-length) algorithm being used to solve the models, as this can accommodate most forms of non-linear load-displacement paths encountered in the analysis of beams.

\subsection{Material modelling}

For the purposes of this investigation, the true material stress-strain behaviour was generated from the engineering stress-strain data obtained from laboratory tests. The relationship between true stress, $\sigma_{\text {true }}$, and engineering stress, $\sigma_{\text {nom }}$ is given by Eq. (7), while the relationship between log plastic strain, $\epsilon_{\text {true }}$, and engineering strain, $\epsilon_{n o m}$, is given by Eq. (8), in which $\sigma_{\text {nom }}$ and $\epsilon_{\text {nom }}$ are the engineering stress and strain respectively and $E$ is the modulus of elasticity.

$$
\begin{gathered}
\sigma_{\text {true }}=\sigma_{\text {nom }}\left(1+\epsilon_{\text {nom }}\right) \\
\epsilon_{\text {true }}=\ln \left(1+\epsilon_{\text {nom }}\right)-\frac{\sigma_{\text {true }}}{E}
\end{gathered}
$$

Material non-linearity was incorporated into the finite-element model by means of a piecewise linear discretisation of the true stress-strain response. Fig. 10 illustrates the discretised tensile stress-strain relationships for the flanges. In the analysis, both flange and web tensile stress-strain relationships were used. 


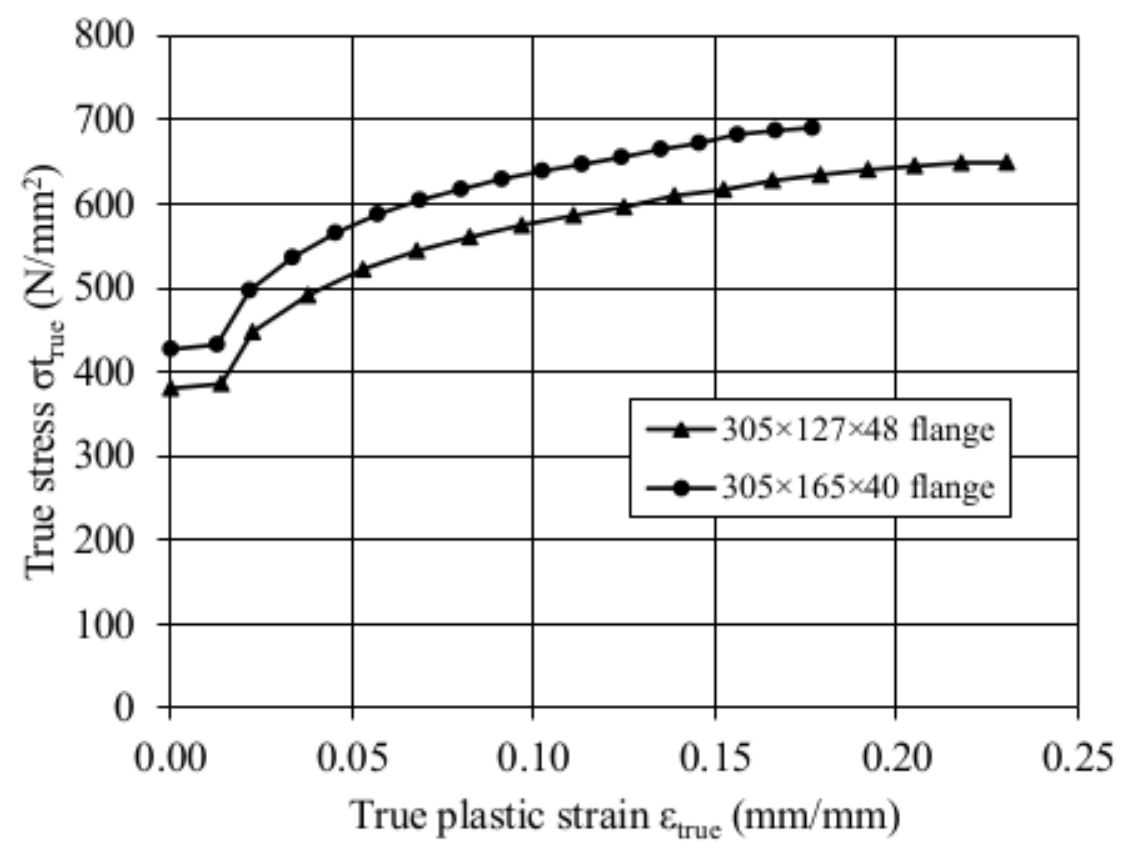

Figure 10: Discrete tensile true stress-true strain relationships for flanges used for finite element modelling.

\subsection{Initial geometric imperfections}

The behaviour of structural members can be significantly influenced by the magnitude and nature of any initial geometric imperfections. In this study, both global lateral imperfections and local plate imperfections are considered. Global imperfections influence the manner and extent to which lateral deflections propagate throughout the loading history and hence the point of initiation of yielding.

Both the locally and globally imperfect geometries of all the members were determined using an initial elastic eigenvalue analysis with the resulting local and global eigenmodes being used to define the distribution of local and global imperfections. Global imperfection amplitudes were taken to be either measured or assumed $(L / 500)$ values of $e_{0}$.

Local eigenmodes were scaled using both measured, $\omega_{0}$, and assumed peak amplitudes. Assumed peak amplitudes were determined from a fraction of the local flange material thickness $(t / 100)$ as well as being derived from the modified value, $\omega_{D W}$, of Dawson and Walker 
[11] by Gardner and Nethercot [12], which is defined in Eq. (9).

$$
\frac{\omega_{D W}}{t}=0.028\left(f_{y} / \sigma_{c r}\right)^{1 / 2}
$$

in which $f_{y}$ is the yield stress and $\sigma_{c r}$ is the elastic critical buckling stress of the most slender constituent plate element in the section; comparisons between all three measures are presented in Table 5. For the range of cross-sections considered, finite element results were relatively insensitive to local imperfections; these imperfections were therefore omitted in the parametric studies.

Table 5: Measured and assumed initial local imperfection amplitudes.

\begin{tabular}{cccc}
\hline Specimen & $\begin{array}{c}\text { Measured } \omega_{0} \\
(\mathrm{~mm})\end{array}$ & $\begin{array}{c}\text { Dawson and Walker } \omega_{D W} \\
(\mathrm{~mm})\end{array}$ & $\begin{array}{c}t / 100 \\
(\mathrm{~mm})\end{array}$ \\
\hline $305 \times 127 \times 48 \mathrm{UB}$ & 0.100 & 0.059 & 0.140 \\
$305 \times 165 \times 40 \mathrm{UB}$ & 0.083 & 0.062 & 0.102 \\
\hline
\end{tabular}

\subsection{Residual stresses}

Residual stresses arise in hot-rolled steel sections due to differential cooling after the forming process; these stresses can have a significant effect on the manner in which yield zones develop. Notably, the flange tips are typically found to be in residual compression (due to early cooling), whilst the web-to-flange junction is typically in residual tension (due to later cooling). Residual stresses can be measured by sectioning a member and converting the released strains into stresses; a considerable quantity of data has been gathered in this manner and a survey is presented in Young [13]. The present research utilises an assumed residual stress distribution that is a linearisation of the polynomial distribution used in Nethercot [14]. As suggested by [15], the maximum compressive residual stress, $\sigma_{r c}$, and the maximum tensile residual stress, $\sigma_{r t}$, are both set to $0.3 f_{y}$. 
Similar to Nethercot [14], residual stresses were introduced into the finite element model by partitioning the web and flanges of each cross-section (16 partitions were used); each partition represents a stress level corresponding to the mid-point of the linear variation in stress over the partition length. The stresses were applied using the *INITIAL CONDITIONS command and equilibration of the stresses was achieved through an initial linear perturbation load step.

\subsection{Validation}

To validate the finite element models, all experiments were simulated using measured material and geometric properties, as well as local and global imperfections and the assumed residual stress pattern. In addition, a second round of finite element models that replaced measured with assumed imperfections were produced; in both cases the ultimate capacities, as well as the general moment-rotation responses were compared with those obtained in the laboratory tests.

Fig. 11 compares overall non-dimensional moment-rotation behaviour of a three-point bending test speciment against the finite element model. Table 6 compares ultimate applied loads obtained from the experiments with those obtained from the two finite element models. The average ratio of test ultimate load to finite element ultimate load where measured and assumed imperfections are used are 0.997 and 0.996 respectively; the corresponding coefficients of variation are 0.001 and 0.001 . For the three-point bending models, the ultimate FE moments are those that correspond to the ultimate test rotation, as testing was stopped due to a lack of vertical displacement capacity in the testing rig. In the subsequent analysis, the assumed imperfection magnitudes will be adopted as they represent a standardised approach that can be easily reproduced and extended.

\subsection{Parametric studies}

Having validated the model against the additional three-point experimental data, in which the restraint spacing was varied, a series of parametric studies was performed, focus- 


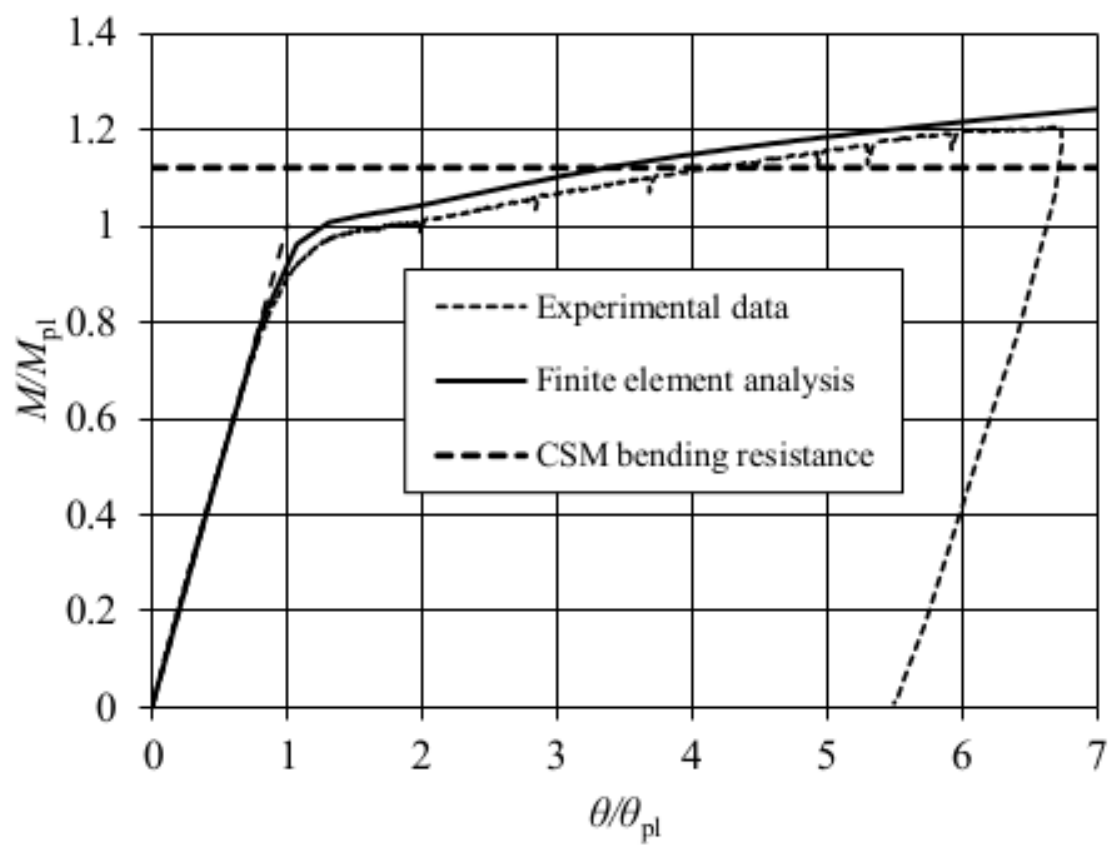

Figure 11: Normalised moment-rotation curves for a tested $305 \times 127 \times 48$ UB ( $\left.\bar{\lambda}_{\mathrm{LT}}=0.1\right)$ specimen subjected to three-point bending and the corresponding finite element model with measured initial geometric imperfections and an assumed residual stress distribution. 
ing on variations in $\bar{\lambda}_{\mathrm{LT}}$, as defined in Eq. (1). The parametric studies were performed on both of the cross-sections used in the testing programme $(305 \times 127 \times 48 \mathrm{UB}$ and $305 \times 165 \times 40$ UB ) corresponding to local flange plate slenderness values of $\bar{\lambda}_{\mathrm{p}}=0.31$ and 0.57 respectively. An further section based on the $305 \times 127 \times 48$ UB was also created with a local flange plate slenderness of $\bar{\lambda}_{\mathrm{p}}=0.45$. A summary of the lateral torsional slenderness values used in the parametric studies are reported in Table 7. It is evident from collecting available experimental data that few tests have been performed on beams whose non-dimensional slenderness values lie in the region $0<\bar{\lambda}_{\mathrm{LT}}<0.4$; the purpose of the parametric study is to bridge this gap for the sections considered. 


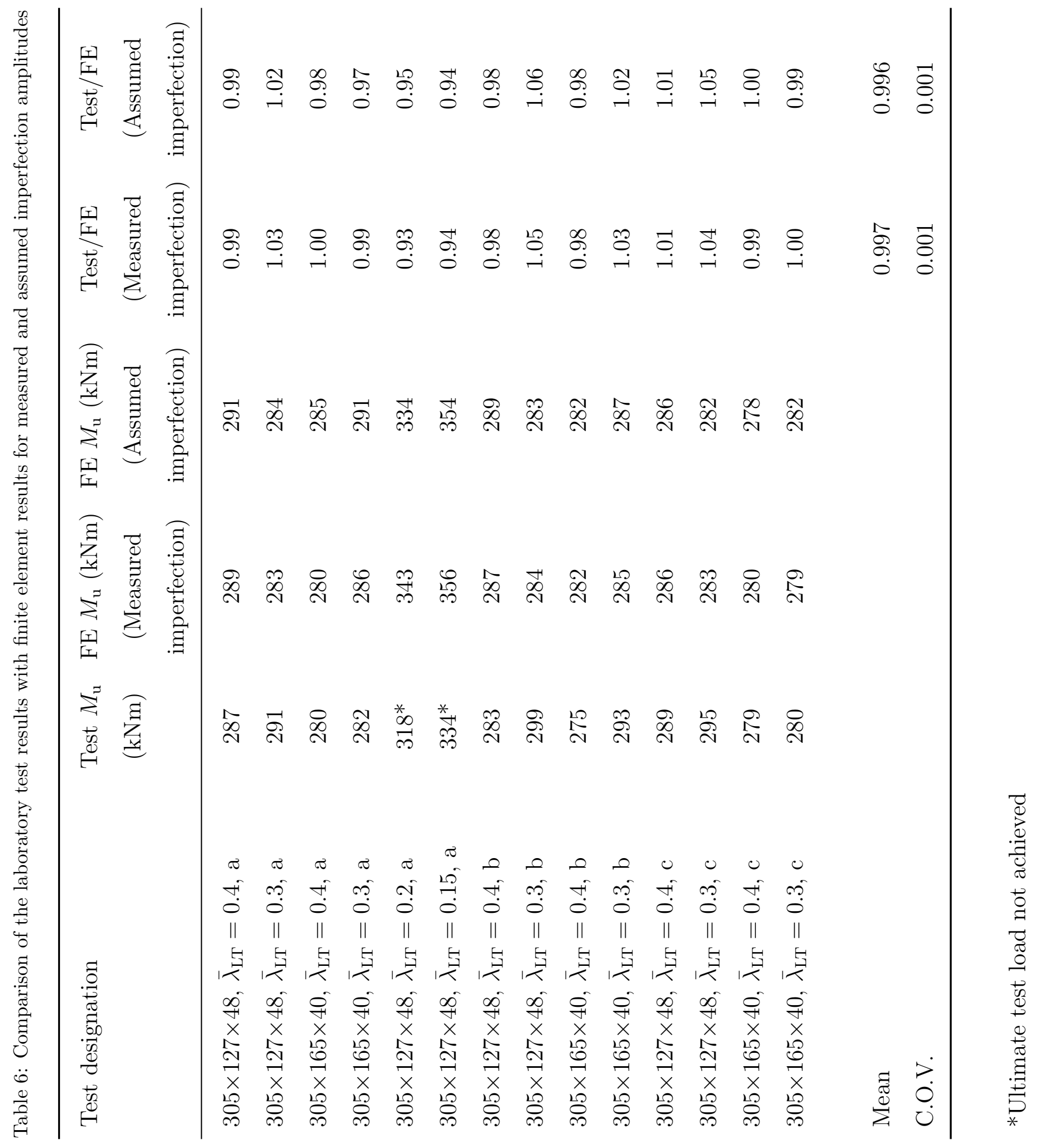


Table 7: Values of $\bar{\lambda}_{\mathrm{LT}}$ used in the parametric studies.

\begin{tabular}{ccc}
\hline & $\bar{\lambda}_{\mathrm{LT}}$ & \\
$\bar{\lambda}_{\mathrm{p}}=0.31$ & $\bar{\lambda}_{\mathrm{p}}=0.45$ & $\bar{\lambda}_{\mathrm{p}}=0.57$ \\
\hline 0.05 & 0.05 & 0.05 \\
0.10 & 0.10 & 0.10 \\
0.15 & 0.14 & 0.13 \\
0.19 & 0.18 & 0.16 \\
0.24 & 0.23 & 0.24 \\
0.29 & 0.27 & 0.27 \\
0.38 & 0.40 & 0.29 \\
0.43 & 0.45 & 0.32 \\
0.48 & 0.49 & 0.42 \\
\hline
\end{tabular}




\section{Lateral restraint spacing}

Currently EN 1993-1-1 defines a non-dimensional slenderness limit, or plateau length, $\bar{\lambda}_{\mathrm{LT}}=0.4$, below which, the effects of lateral torsional buckling can be ignored. Tests conducted in this study, as well as additional tests from the literature, have demonstrated that this limit is reasonable when the moment capacity is limited to $M_{\mathrm{pl}}$, as in current design approaches, but may need to be reduced when strain-hardening is exploited in design, as is the case in the CSM. In this section, equations are developed to form the preliminary basis for a new CSM lateral torsional buckling slenderness limit, taking into consideration the key CSM parameters of cross-section geometry and the rate of strain hardening $E / E_{\mathrm{sh}}$.

\subsection{Analytical study}

An analytical study to consider the effect of exploiting strain-hardening in beams upon the lateral restraint spacing requirements, as characterised by $\bar{\lambda}_{\mathrm{LT}}$, is conducted to gain insight into the key underlying parameters controlling the physical behaviour. The analysis will be of a simply supported beam subjected to a uniform bending moment which will result in a region of constant curvature along the length of the beam and no shearing forces. In so doing, the following assumptions are made:

(i) The beam is initially straight and free of imperfections.

(ii) Residual stresses are neglected.

(iii) The ends of the flanges are free to warp but cannot displace or twist (simple support end conditions).

(iv) The material is assumed to behave elastically with a Young's modulus $E$ up until the yield stress $f_{y}$, immediately after which work hardening will commence with a hardening modulus $E_{\mathrm{sh}}$ until the limiting (local buckling) strain $\epsilon_{\mathrm{csm}}$ is reached, and because of this, local buckling is assumed to be absent.

\subsection{Elastic buckling equation}

Buckling can be described as the behaviour in which a structure or a structural element suddenly deforms in a plane different to the original plane of loading and response [16]. The 
current elastic theory of flexural- or lateral-torsional buckling that is widely presented in textbooks (see Bleich [17] and Timoshenko and Gere [18]) has its underpinnings in the work presented by Euler [19] on the flexural buckling analysis of slender columns, as well as the studies by Saint-Venant [20] on the twisting response of members subjected to uniform torsion. In two independent studies published in the same year by Prandtl [21] and Michell [22], a unified theory considering both the flexural and torsional buckling behaviour of beams of a narrow rectangular cross-section subject to transverse loading was presented, the solution of which was in the form of a second-order differential equation in displacement and twist. Subsequent contributions by Timoshenko [23], Timoshenko [24] and Wagner [25] which included the effects of warping torsion in I-sections, led to the development of a general theory of lateral torsional buckling.

The equation relating the elastic critical buckling moment $M_{c r}$ of a beam to the laterally unsupported span L, as derived by Timoshenko and Gere [18], is given by Eq. (10):

$$
\frac{M_{\mathrm{cr}}}{M_{\mathrm{pl}}}=\frac{\pi}{M_{\mathrm{pl}} L} \sqrt{E I_{z} G I_{t}\left(1+\frac{\pi^{2} E I_{w}}{L^{2} G I_{t}}\right)}
$$

in which $E$ and $G$ are the elastic and shear moduli, $I_{z}$ is the minor axis second moment of area, $I_{w}$ is the warping constant and $I_{t}$ is the St. Venant's torsion constant. Eq. (10) represents the positive eigenvalue of the differential equation for lateral torsional buckling under pure moment with the following boundary conditions:

$$
u=\frac{\mathrm{d}^{2} u}{\mathrm{~d} x^{2}}=\phi=\frac{\mathrm{d}^{2} \phi}{\mathrm{d} x^{2}}=0 \quad \text { at } \quad x=0 \quad \text { and } \quad x=L
$$

where $u$ is the lateral displacement from the longitudinal centroidal axis $x$ and $\phi$ is the angle of twist about the centroid. Defining the general stiffness values $B_{z}=E I_{z}, C_{t}=G I_{t}$, and where $h$ is the overall height of the cross-section, $C_{w}=E I_{w}=(1 / 4) E I_{z} h^{2}$, Eq. (10) can be generalised to account for inelastic buckling with the introduction of bending and warping stiffness reduction parameters $\tau_{1}$ and $\tau_{2}$ respectively. The parameters $0 \leq \tau_{1} \leq 1$ 
and $0 \leq \tau_{2} \leq 1$, which are dependent upon the degree of yield penetration $\alpha$ and hence the yielded area $\eta$, serve as a means of reducing bending and warping stiffness values below their elastic values as yield progresses through the cross-section.

\subsection{Cross-section resistance dependent upon yield penetration}

The design expression for the CSM moment of resistance (Eq. (2)) can be parameterised in terms of yield penetration, $\alpha$. In light of previous work on the CSM [2], it is assumed that the material is elastic, linear hardening, with a strain-hardening slope $E_{s h}=E / 100$ and with a limiting strain, $\epsilon_{\mathrm{csm}}$. $\epsilon_{\mathrm{csm}}$ is defined using Eq. (3), which is derived from an empirical relationship between local buckling and non-dimensional plate slenderness. The constitutive relationship used in the CSM is summarised in Fig. 12.

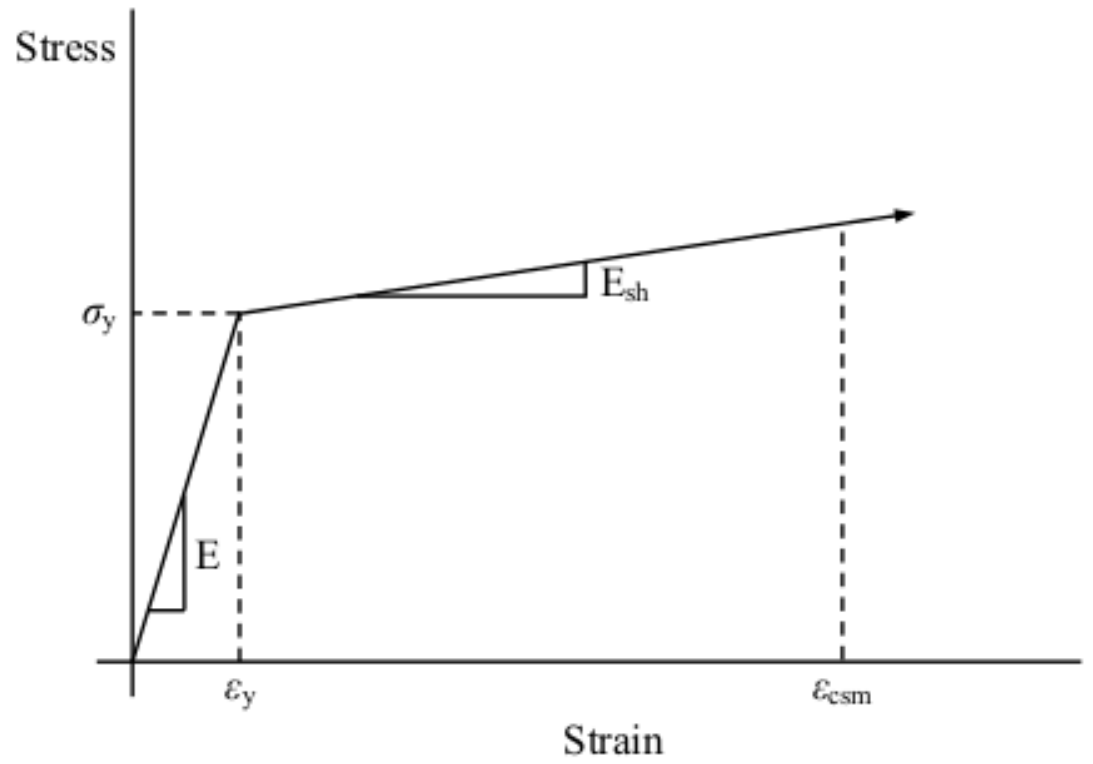

Figure 12: The constitutive model used for the CSM.

In a similar approach to previous work $[1,2]$, moment equilibrium can be considered by integrating the stress through the depth of the section, derived from the adopted material model and assuming plane sections remain plane. In the present work, analytical expressions 
for moment capacity are derived in terms of the degree of yield penetration $\alpha$, where $\alpha=1$ denotes first yield and $\alpha=0$ denotes full cross-section yield penetration (see Fig. 13). Table 8 presents expressions for moment capacities for the cases when (a) the flange is partially yielded and (b) when the flange is fully yielded and the web is partially yielded; these are based upon the definitions shown in Fig. 13, which also depicts the assumed linear variation in strain throughout the cross-section. In this table, the superscript $I$ denotes expressions that correspond with a partially yielded flange and an elastic web, whilst the superscript II denotes expressions that correspond with a fully yielded flange and a partially yielded web; all expressions can be defined from Fig. 13.

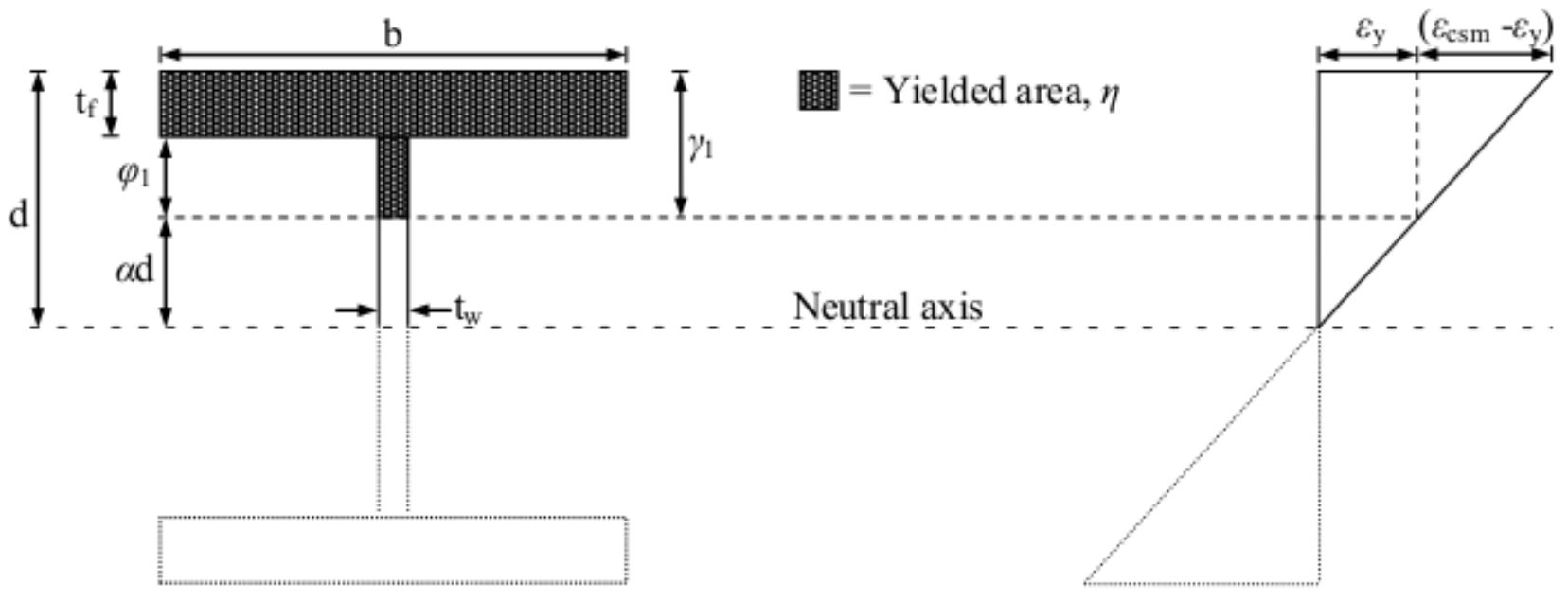

Figure 13: Cross-section definitions and strain distribution for determining cross-section bending resistance.

When $E_{\text {sh }}=\alpha=0$, the fully plastic moment is defined and this will be used as a numraire in subsequent analysis. For a typical I-section $(305 \times 127 \times 48 \mathrm{UB})$, the relationship between yielded area $\eta$ and moment capacity, allowing for strain-hardening, is shown in Fig. 14. This shows that beyond $M_{\mathrm{pl}}$, all of the minor axis rigidity is provided by the web.

\subsection{Stiffness reduction parameters}

In order to develop an expression for the inelastic buckling moment, a relationship needs to be developed between cross-section moment, $M$, yield proportion, $\alpha$, and out of plane 
Table 8: Parameter definitions for the yield-dependent CSM moment capacity expressions.

\begin{tabular}{|c|c|}
\hline $1>\alpha>\alpha_{\lim }$ & $\alpha_{\lim }>\alpha>0$ \\
\hline$\gamma_{1}=(1-\alpha)$ & $\varphi_{1}=\gamma_{1}-t_{f}$ \\
\hline$\gamma_{2}=t_{f}-\gamma_{1}$ & $\varphi_{2}=\alpha d$ \\
\hline$\beta_{1}^{I}=\epsilon_{\mathrm{y}}\left(1-t_{f}\right) / \varphi_{2}$ & $\beta_{1}^{I I}=\left(\epsilon_{\mathrm{csm}} / d\right) \varphi_{1}$ \\
\hline$\beta_{2}^{I}=\epsilon_{\mathrm{y}}-\beta_{1}^{I}$ & $\beta_{2}^{I I}=\left(\epsilon_{\mathrm{csm}}-\epsilon_{\mathrm{y}}\right)-\beta_{1}^{I I}$ \\
\hline$\mu_{1}^{I}=\alpha d+(1 / 2) \gamma_{1}$ & $\mu_{1}^{I I}=d-(1 / 2) t_{f}$ \\
\hline$\mu_{2}^{I}=\alpha d+(2 / 3) \gamma_{1}$ & $\mu_{2}^{I I}=d-(1 / 3) t_{f}$ \\
\hline$\mu_{3}^{I}=\left(d-t_{f}\right)+(1 / 2) \gamma_{2}$ & $\mu_{3}^{I I}=\varphi_{2}+(1 / 2) \varphi_{1}$ \\
\hline$\mu_{4}^{I}=\left(d-t_{f}\right)+(2 / 3) \gamma_{2}$ & $\mu_{4}^{I I}=\varphi_{2}+(2 / 3) \varphi_{1}$ \\
\hline$\mu_{5}^{I}=(2 / 3)\left(d-t_{f}\right)$ & $\mu_{5}^{I I}=(2 / 3) \varphi_{2}$ \\
\hline$M_{1}^{I}=\gamma_{1} \epsilon_{\mathrm{y}} \mu_{1}^{I} b E$ & $M_{1}^{I I}=t_{f} \epsilon_{\mathrm{y}} \mu_{1}^{I I} E b$ \\
\hline$M_{2}^{I}=(1 / 2) \gamma_{1}\left(\epsilon_{\mathrm{csm}}-\epsilon_{\mathrm{y}}\right) \mu_{2}^{I} b E_{\mathrm{sh}}$ & $M_{2}^{I I}=t_{f}\left(\beta_{1}^{I I} \mu_{1}^{I I}+(1 / 2) \beta_{2}^{I I} \mu_{2}^{I I}\right) b E_{\mathrm{sh}}$ \\
\hline$M_{3}^{I}=\gamma_{2} \beta_{1}^{I} \mu_{3}^{I} b E$ & $M_{3}^{I I}=\varphi_{1} \epsilon_{\mathrm{y}} \mu_{3}^{I I} t_{w} E$ \\
\hline$M_{4}^{I}=(1 / 2) \gamma_{2} \beta_{2}^{I} \mu_{4}^{I} b E$ & $M_{4}^{I I}=(1 / 2) \varphi_{1}\left(\epsilon_{\mathrm{csm}}-\epsilon_{\mathrm{y}}\right) \mu_{4}^{I I} t_{w} E_{\mathrm{sh}}$ \\
\hline$M_{5}^{I}=(1 / 2)\left(d-t_{f}\right) \beta_{1}^{I} \mu_{5}^{I} t_{w} E$ & $M_{5}^{I I}=(1 / 2) \varphi_{2} \epsilon_{\mathrm{y}} \mu_{5}^{I I} t_{w} E$ \\
\hline$M^{I}=\sum_{i=1}^{5} M_{i}^{I}$ & $M^{I I}=\sum_{i=1}^{5} M_{i}^{I I}$ \\
\hline
\end{tabular}




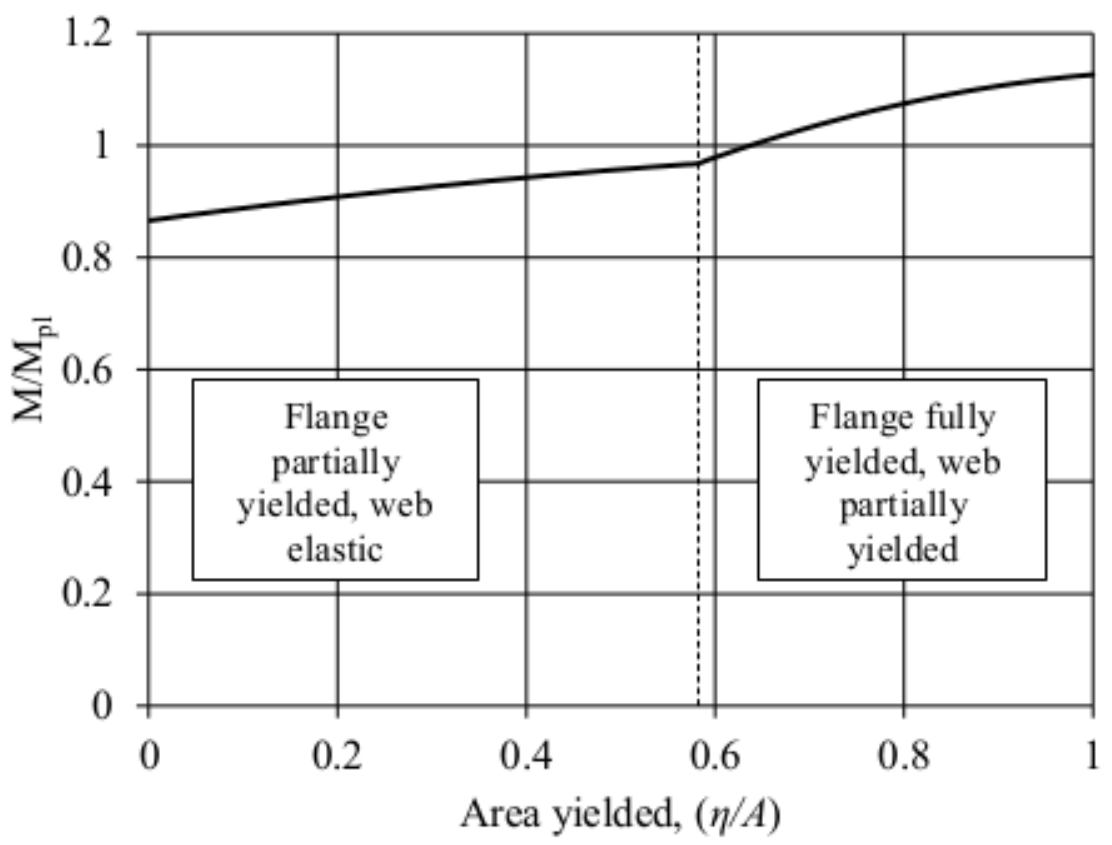

Figure 14: Typical relationship between moment capacity and yielded area for a $305 \times 127 \times 48$ UB.

flexural and warping stiffness. This will be achieved through developing non-dimensional stiffness reduction parameters for out of plane flexural stiffness $\left(\tau_{1}\right)$ and warping $\left(\tau_{2}\right)$, which can then be applied to a generalised version of Eq. (10).

\subsubsection{Minor axis bending stiffness}

Assuming that no reversal of stress occurs anywhere in the cross-section [26], the material stressed beyond yield may be assumed to have a reduced modulus of $E_{\mathrm{sh}}=E / 100$, with the unyielded material possessing its full elastic stiffness $E$. Noting that for any rectangular section of depth $t$ and width $b, I_{y}=b t^{3} / 12$. Thus for the partially yielded flange the minor axis bending stiffness will be:

$$
B^{I}=\frac{1}{12}\left[\left(A_{f}-\eta\right) b^{2}+A_{w} t_{w}^{2}\right] E+\frac{1}{12} \eta b^{2} E_{\mathrm{sh}}
$$

in which $A_{f}$ is the area of the flange and $A_{w}$ is the area of the web. For the partially yielded web and fully yielded flange, the minor axis stiffness will be: 


$$
B^{I I}=\frac{1}{12}\left[A_{w}-\left(\eta-A_{f}\right)\right] t_{w}^{2} E+\frac{1}{12}\left[A_{f} b^{2}+\left(\eta-A_{f}\right) t_{w}^{2}\right] E_{\mathrm{sh}}
$$

Reduced minor axis bending stiffness can then be obtained by comparing $B^{I}$ and $B^{I I}$ with $B_{z}$ over the relevant range of yield penetration:

$$
\tau_{1}(\alpha)= \begin{cases}\frac{B^{I}}{B_{z}} & 1>\alpha>\alpha_{\lim } \\ \frac{B^{I I}}{B_{z}} & \alpha_{\lim }>\alpha>0\end{cases}
$$

The relationship between yielded area $\eta$ normalised by full cross-section area and normalised minor axis bending stiffness is illustrated in Fig. 15 which shows that once the flange has yielded, the available minor axis rigidity provided by the web is approximately $1 \%$ of the minor axis rigidity available at first yield.

The relationship between normalised minor axis bending stiffness and non-dimensional moment capacity is illustrated in Fig. 16 which shows that the minor axis flexural rigidity is reduced considerably as $M_{\mathrm{pl}}$ is approached.

\subsubsection{Torsional stiffness}

It has been demonstrated both experimentally and theoretically that, for partially plastic narrow beams, the initial torsional rigidity maintains its elastic value [27]; subsequent experimental work on a tube strained into the inelastic range has shown similar results [28]. On this basis, no reduction factor for torsional rigidity $C_{t}$ will be provided and it will be assumed that $C_{t}=G I_{t}$ will remain independent of $\alpha$.

\subsubsection{Warping stiffness}

It has been shown that warping rigidity is an influential factor on the critical moment for thin-walled open sections [29]. Assuming that all of the warping resistance is provided 


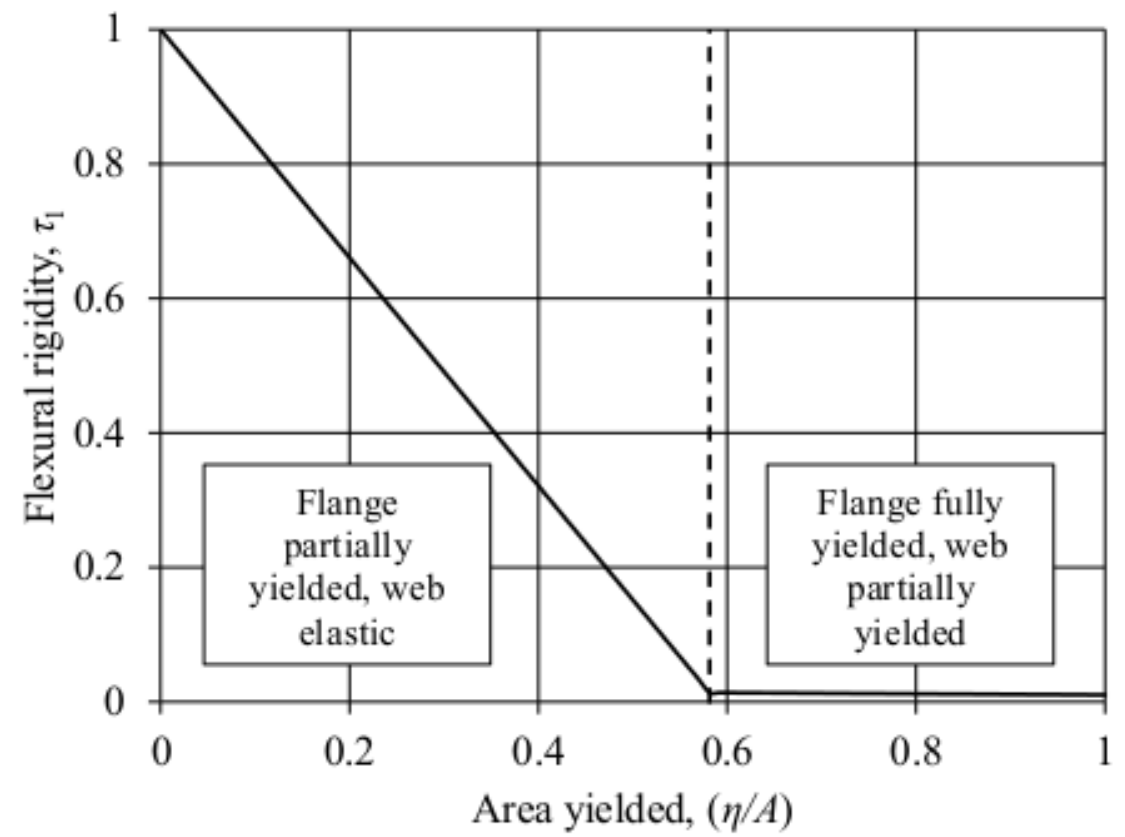

Figure 15: Typical relationship between yielded area and bending stiffness for a $305 \times 127 \times 48 \mathrm{UB}$.

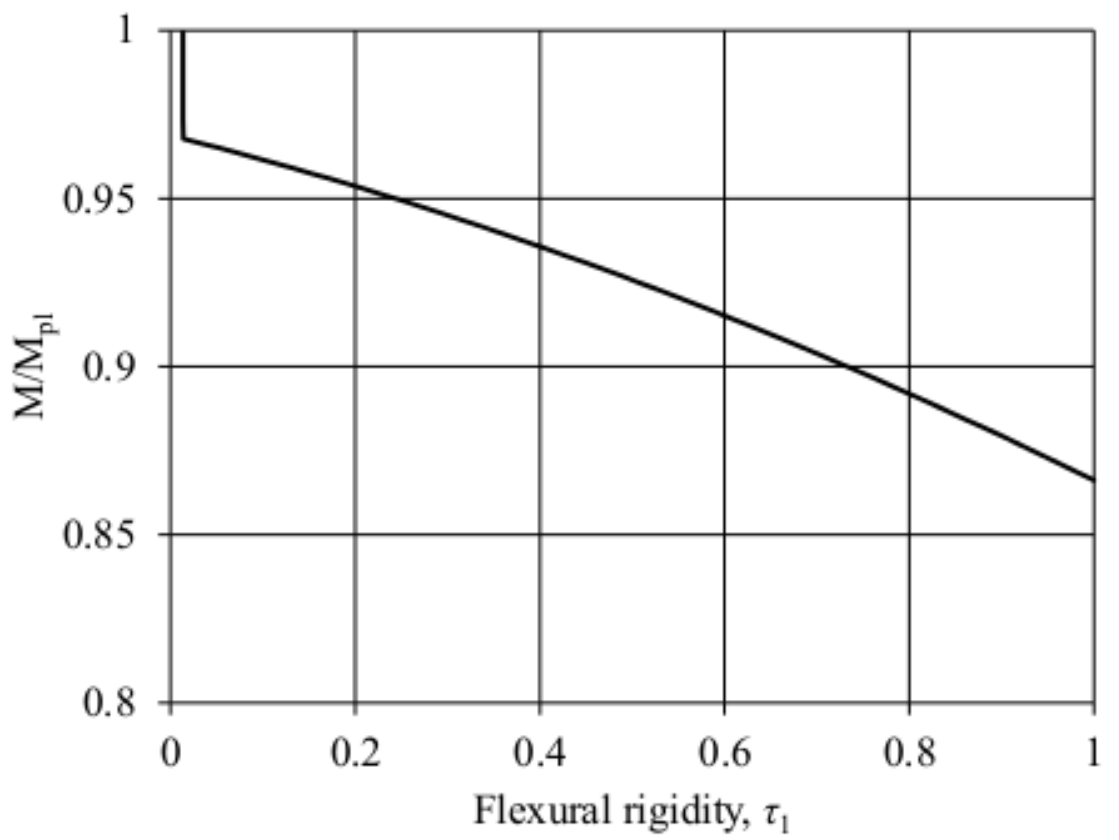

Figure 16: Typical relationship between bending stiffness and cross-section moment capacity for a $305 \times$ $127 \times 48$ UB. 
by the flanges, the relationship between non-dimensional warping stiffness, $\tau_{2}$, and yield penetration, $\alpha$, is identical to $\tau_{1}$ in the range $1>\alpha>\alpha_{\text {lim }}$ and zero thereafter:

$$
\tau_{2}(\alpha)= \begin{cases}\tau_{1}(\alpha) & 1>\alpha>\alpha_{\lim } \\ 0 & \alpha_{\lim }>\alpha>0\end{cases}
$$

\subsection{The CSM buckling equation}

Introducing the generalised terms for stiffness defined in Section 5.2 and applying the non-dimensional stiffness reduction factors defined in Eqs. (14) and (15), the critical nondimensional bending moments for an in inelastic beam with strain-hardening over the range $\left(\epsilon_{\mathrm{csm}}-\epsilon_{\mathrm{y}}\right)$ are given by Eq. (16):

$$
\frac{M_{\mathrm{cr}}}{M_{\mathrm{pl}}}=\frac{\pi}{M_{\mathrm{pl}} L} \sqrt{B_{z} C_{t} \tau_{1}\left(1+\frac{\pi^{2} C_{w} \tau_{2}}{L^{2} C_{t}}\right)}
$$

This can be re-written in terms of the critical buckling length $L_{c r}$ :

$$
L=\sqrt{\sqrt{D}-\frac{B}{2 A}}
$$

where

$$
\begin{aligned}
A=\left(\frac{M_{\mathrm{cr}}}{M_{\mathrm{pl}}}\right)^{2}, \quad B & =-\frac{\pi^{2} B_{z} C_{t} \tau_{1}}{M_{\mathrm{pl}}^{2}}, \quad C=-\frac{\pi^{4} B_{z} C_{w} \tau_{1} \tau_{2}}{M_{\mathrm{pl}}^{2}} \text { and } \\
D & =\left(\frac{B}{2 A}\right)^{2}-\frac{C}{A}
\end{aligned}
$$

Having developed relationships between $M, \alpha, \tau_{1}$ and $\tau_{2}$, assumed values of $M_{\mathrm{cr}} / M_{\mathrm{pl}}$ can now be used to obtain corresponding critical buckling lengths for the CSM. 


\subsubsection{Comparison to experimental and numerical data}

Using the experimental data obtained from the tests and the literature described in Section 3, as well as the numerical data generated in the main parametric study (Section 4.7), the performance of Eq. (16) for a range of cross-sections is assessed (Fig. 17).

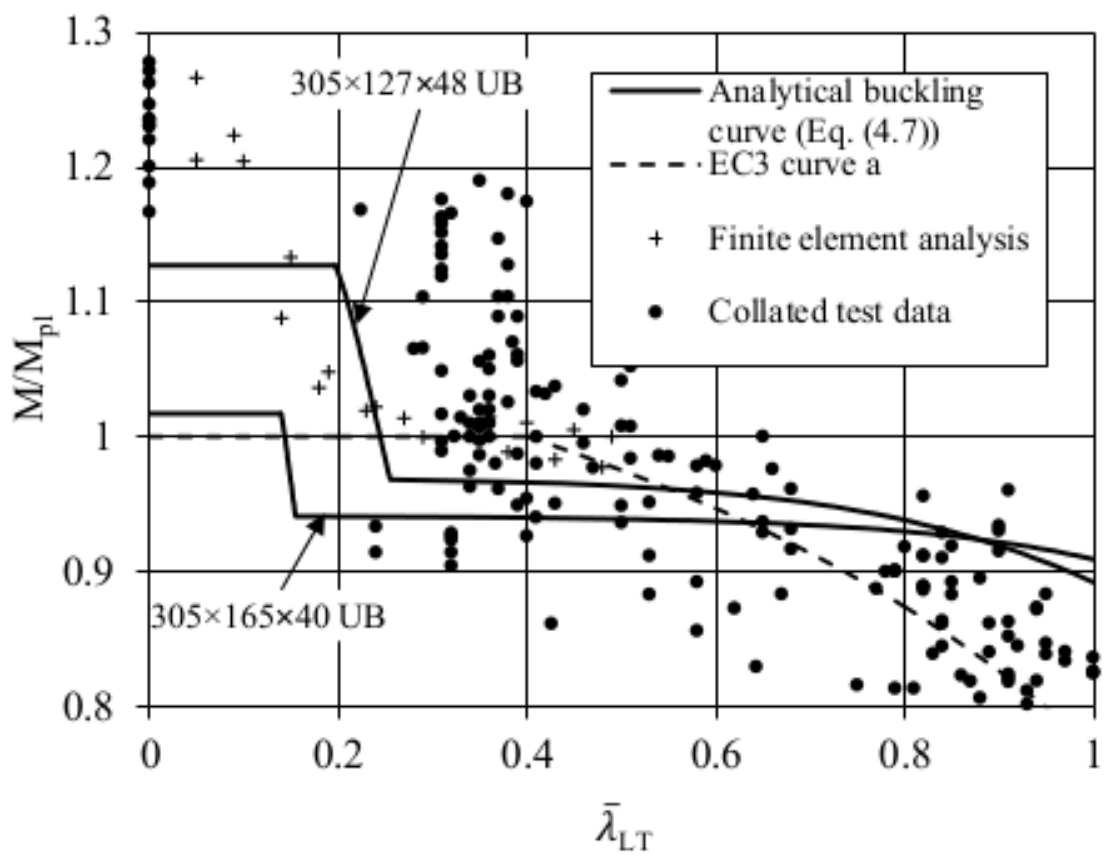

Figure 17: The CSM member buckling equation, experimental and numerical data.

Although there is considerable scatter in the data, experimental results typically lie above Eq. (16) particularly in the low slenderness region of primary interest, making it a conservative prediction for limiting CSM lateral torsional buckling slenderness.

\subsection{Response to key design parameters}

The Continuous Strength Method is dependent upon two key design parameters: crosssection geometry and the rate of strain-hardening $\left(E / E_{\mathrm{sh}}\right)$. This section will examine the sensitivity of Eq. (16) to these parameters and with the aim to provide an indicative range 
of limiting $\bar{\lambda}_{\mathrm{LT}}$ values for the CSM, below which the full CSM bending resistance $M_{\mathrm{csm}}$ can be achieved. The transition to $M_{\mathrm{pl}}$ will also be examined.

\subsubsection{Cross-section geometry}

Eq. (16) is uniquely defined by cross-section properties. To investigate the influence of cross-section geometry on the limiting CSM slenderness, a practical range of cross-sections was selected; this was achieved by considering all of the commercially available rolled Isections [30]. For each case, the limiting values of $\bar{\lambda}_{\text {LT }}$ at which the CSM capacities of each cross-section can be attained were determined. The values are plotted against $b / t_{f}$ (where $b$ is the flange width and $t_{f}$ is the flange thickness) in Fig. 18. It may be observed that the limiting values of $\bar{\lambda}_{\mathrm{LT}}^{\mathrm{csm}}$ for $M_{\mathrm{csm}}$ lie in the range $0.13 \leq \bar{\lambda}_{\mathrm{LT}} \leq 0.26$.

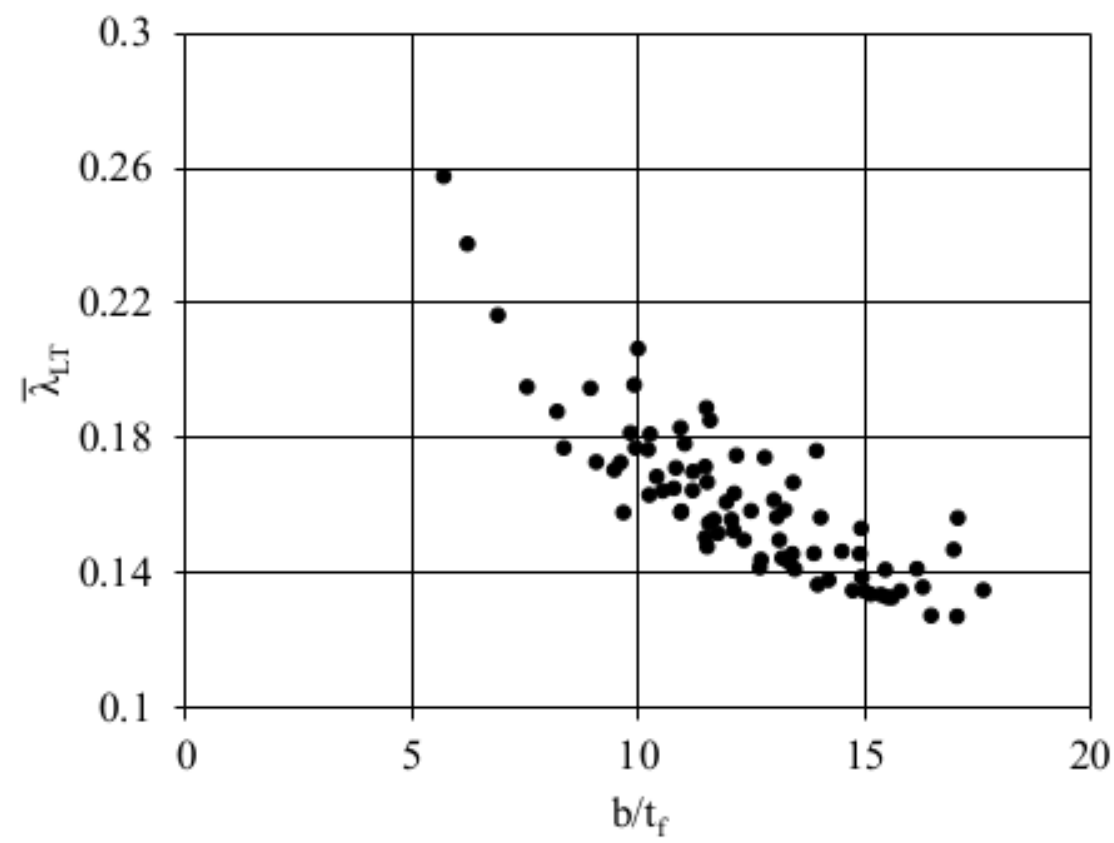

Figure 18: Influence of cross-section geometry (expressed in terms of $b / t_{f}$ ) on limiting slenderness $\bar{\lambda}_{\mathrm{LT}}^{\mathrm{csm}}$ for commercially available cross-sections.

\subsubsection{Rate of strain-hardening}

The ratio of Young's modulus to strain-hardening modulus $E / E_{\mathrm{sh}}$ is currently assumed to be fixed at $E / E_{\mathrm{sh}}=100$, in line with $\mathrm{EN} 1993-1-5$. Introducing increased rates of $E_{\mathrm{sh}}$ not 
only enhances the CSM capacity at the cross-section level, but also permits a small increase in restraint spacing. Fig 19 shows the effect of varying values of $E / E_{\text {sh }}$ in equally spaced increments between $50 \leq E / E_{\mathrm{sh}} \leq 100$ on the maximum value of $\bar{\lambda}_{\mathrm{LT}}$ at which $M_{\mathrm{csm}}$ can be attained for the same cross-section geometry; for the range $50 \leq E / E_{\mathrm{sh}} \leq 100$, maximum lateral torsional buckling slenderness values lie in the range $0.19 \leq \bar{\lambda}_{\mathrm{LT}} \leq 0.23$.

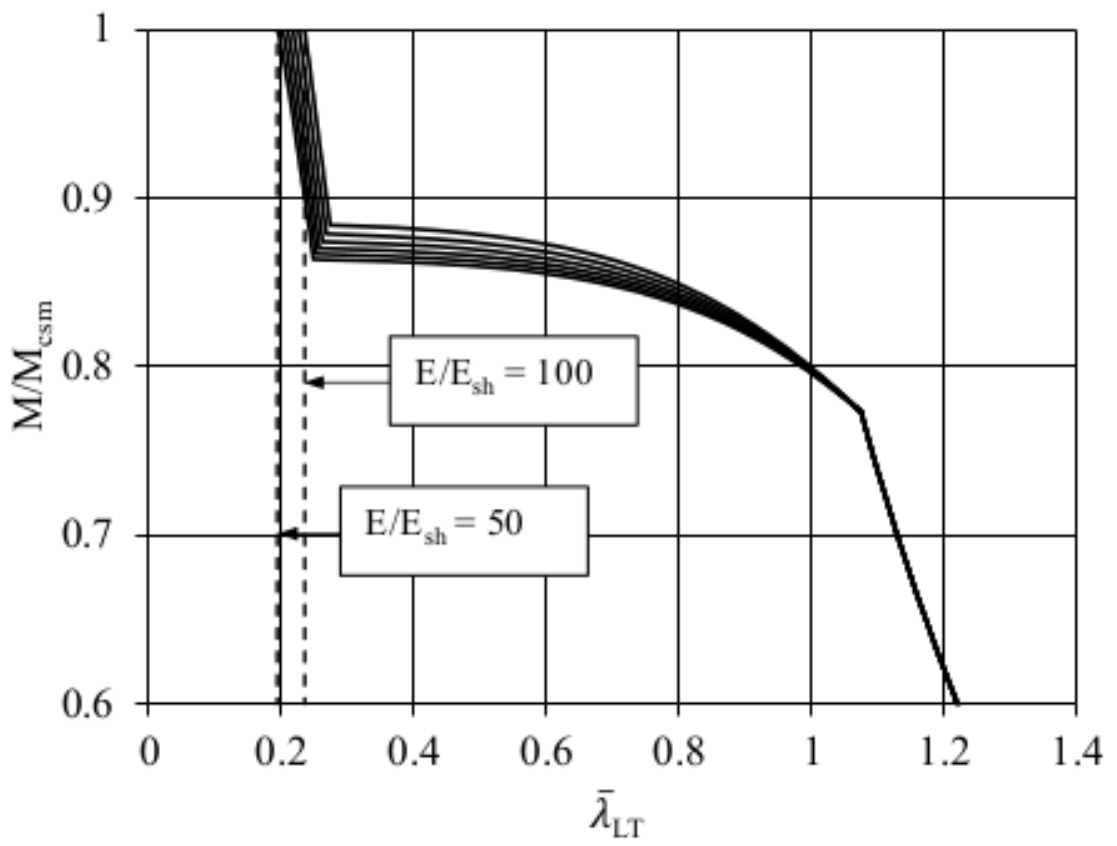

Figure 19: Influence of $E_{\mathrm{sh}}$ on limiting slenderness below which $M_{\mathrm{csm}}$ can be achieved.

From this analysis, it is clear that cross-section geometry is the most significant parameter of the CSM for the purposes of lateral stability.

\section{Preliminary design recommendations}

\subsection{Proposal for limiting slenderness and a transition from $M_{\mathrm{pl}}$ to $M_{\mathrm{csm}}$}

The transition from the plastic moment capacity to the CSM moment capacity, as well as the limiting lateral torsional buckling slenderness, should reflect the basic strain-hardening 
properties of the material as well as lie in reasonable proximity to numerical and experimental data. A previous equivalent proposal by [31] for the limiting slenderness $\bar{\lambda}_{\mathrm{LT}}^{\mathrm{csm}}$ may be expressed as:

$$
\bar{\lambda}_{\mathrm{LT}}^{\mathrm{csm}}=\sqrt{E_{s h} / E}
$$

This may be coupled with a linear transition from $M_{\mathrm{pl}}$ to $M_{\mathrm{csm}}$, given by:

$$
\frac{M}{M_{\mathrm{pl}}}=\frac{\left(\bar{\lambda}_{\mathrm{LT}}-\bar{\lambda}_{\mathrm{LT}}^{\mathrm{csm}}\right)}{0.4-\bar{\lambda}_{\mathrm{LT}}^{\mathrm{csm}}}\left(1-\frac{M_{\mathrm{csm}}}{M_{\mathrm{pl}}}\right)+\frac{M_{\mathrm{csm}}}{M_{\mathrm{pl}}}
$$

This relationship is plotted for two cross-sections in Fig. 20. Compared with numerical data, there is a degree of over-prediction during the transition phase, which could be eliminated by a more sophisticated non-linear transition. For conservative design, it would be sufficient to assume $M_{\mathrm{pl}}$ between $\bar{\lambda}_{\mathrm{LT}}=0.4$ and $\bar{\lambda}_{\mathrm{LT}}^{\mathrm{csm}}$.

\subsection{Refinement using analytical, numerical and test data collected from the literature}

Fig. 21 shows the same experimental and numerical data as Fig. 17, but normalised by $M_{\text {csm }}$ rather than $M_{\mathrm{pl}}$. Additional data points were generated using the analytical model presented in this chapter for commercially available I-sections [30]. From this data, the first observation that can be made is that there is a broad range of $\bar{\lambda}_{\mathrm{LT}}$ values at which $M_{\mathrm{csm}}$ can be attained, typically in the range $0.15 \leq \bar{\lambda}_{\mathrm{LT}} \leq 0.4$ (although the main concentration of data is in the range $0.15 \leq \bar{\lambda}_{\mathrm{LT}} \leq 0.25$ ); all of these values exceed the value conservatively suggested by $\bar{\lambda}_{\mathrm{LT}}^{\mathrm{cs}}$ in Eq. (18). From this observation, and the collected dataset, it may be reasonable to suggest that the practical slenderness limit for attaining $M_{\mathrm{csm}}$ at the member level can be revised to $\bar{\lambda}_{\mathrm{LT}}=0.2$.

The second observation is that between $0 \leq \bar{\lambda}_{\mathrm{LT}} \leq 0.2$, the majority of the available data exceeds $M_{\mathrm{csm}}$, which supports setting the limiting slenderness to $\bar{\lambda}_{\mathrm{LT}}=0.2$. Indeed, making further reference to Fig. 17, a proportion of the specimens between $0.2 \leq \bar{\lambda}_{\mathrm{LT}} \leq 0.4$ lie below 


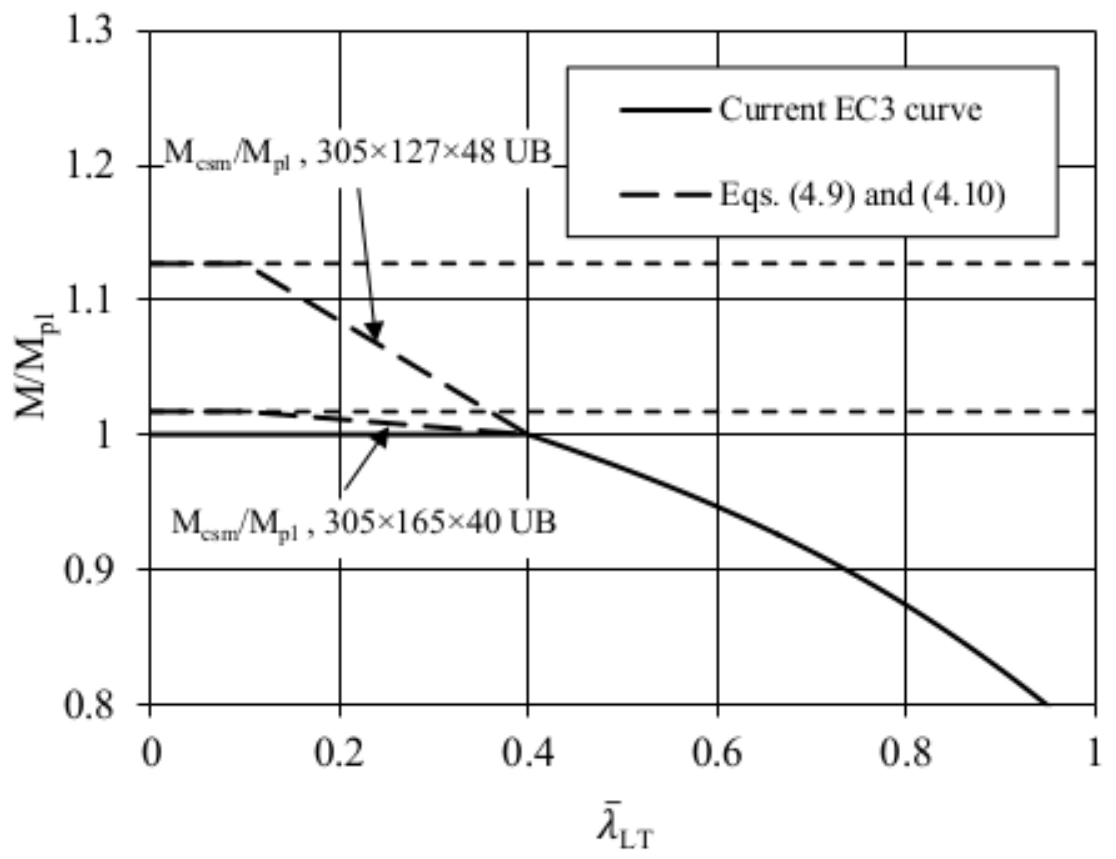

(a) Proposed transition curve assuming $E / E_{\text {sh }}=100$ for cross-sections with $\bar{\lambda}_{\mathrm{p}}=0.31$ and $\bar{\lambda}_{\mathrm{p}}=$ 0.57

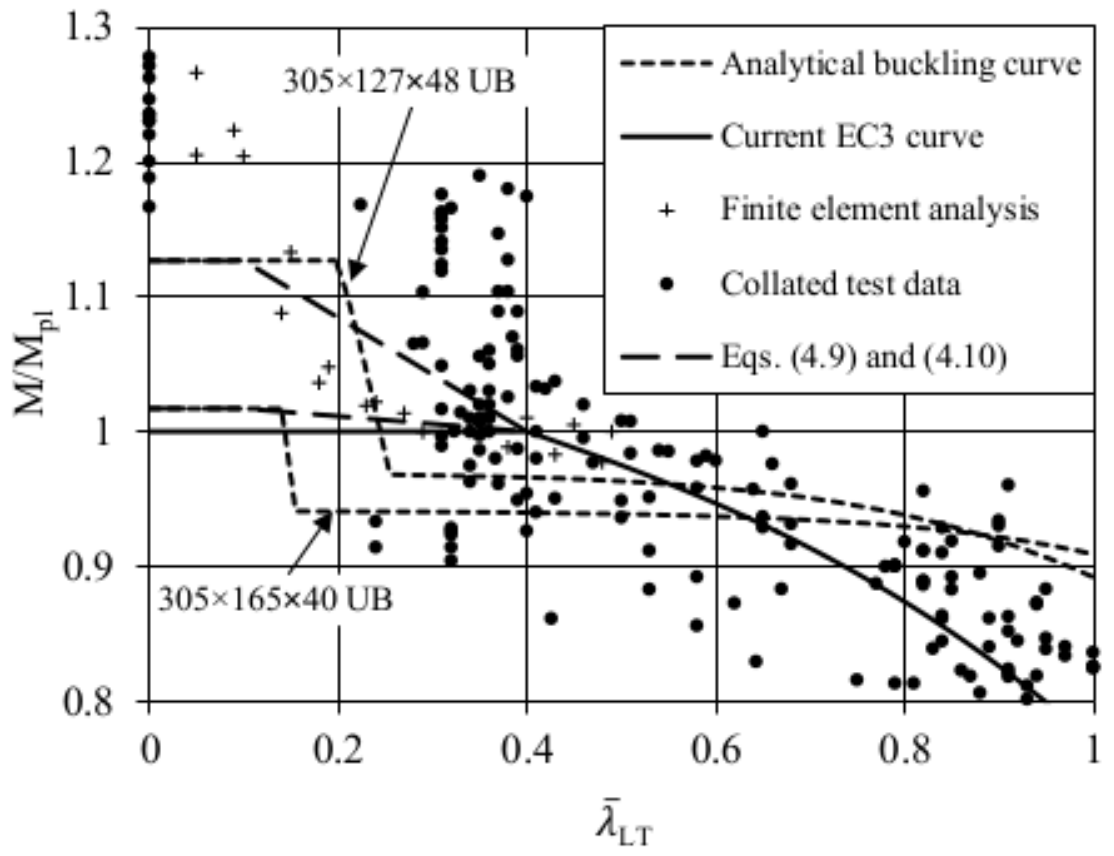

(b) Comparison of transition curves to analytical, finite element and experimental data.

Figure 20: Example $M_{\mathrm{pl}}$ to $M_{\mathrm{csm}}$ transition curves. 


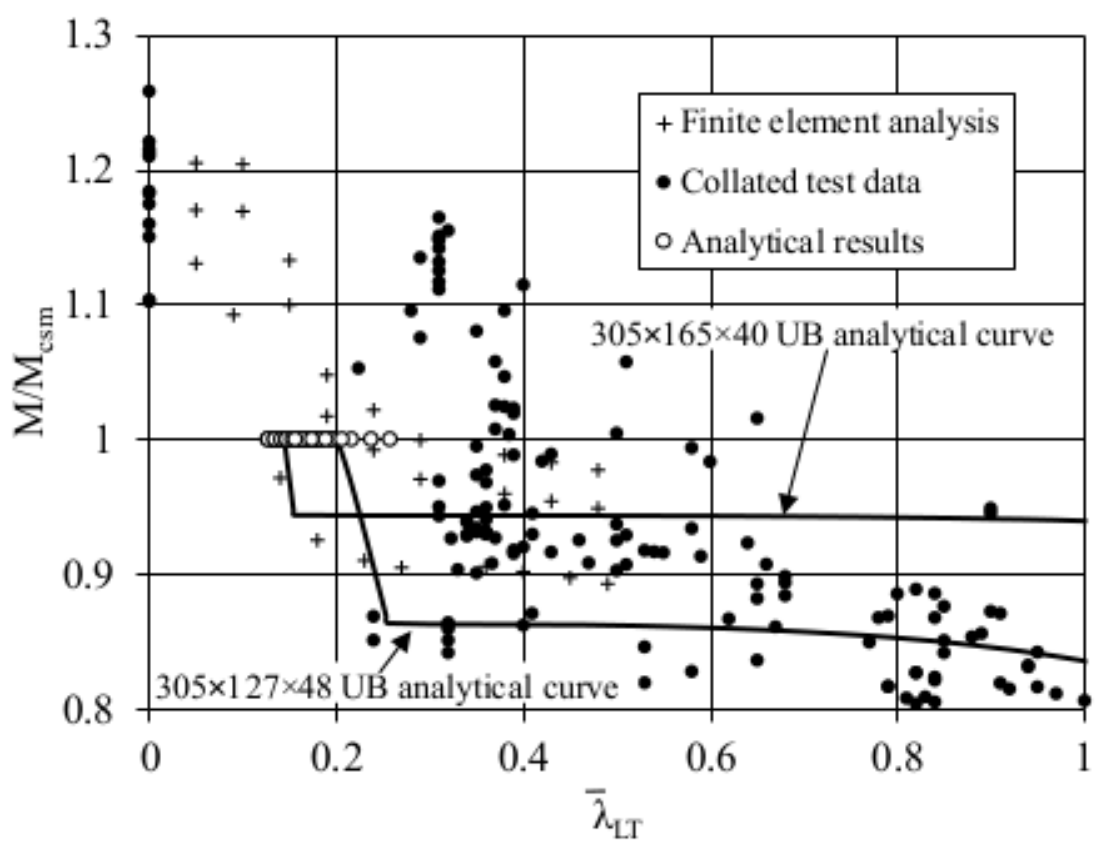

Figure 21: Collated analytical, numerical and experimental data normalised by $M_{\mathrm{csm}}$.

$M_{\mathrm{pl}}$, which suggests that the current plateau limit of $\bar{\lambda}_{\mathrm{LT}}=0.4$ for traditional plastic design set out in EN 1993-1-1 also caters for most, but not all of the test data. By this analogy, a general plateau length of $\bar{\lambda}_{\mathrm{LT}}=0.2$ for the CSM can be considered to be an acceptable initial proposal.

In the light of these observations the following design equation is recommended (Eq. (20)):

$$
\chi_{\mathrm{LT}, \mathrm{csm}}=\frac{\left(\bar{\lambda}_{\mathrm{LT}}-0.2\right)}{0.2}\left(1-\frac{M_{\mathrm{csm}}}{M_{\mathrm{pl}}}\right)+\frac{M_{\mathrm{csm}}}{M_{\mathrm{pl}}} \quad \text { for } \quad 0.2 \leq \bar{\lambda}_{\mathrm{LT}} \leq 0.4
$$

in which $\chi_{\mathrm{LT}, \mathrm{csm}}$ is a factor applied to $M_{\mathrm{pl}}$ to obtain $M_{\mathrm{csm}}$ in the region $0.2 \leq \bar{\lambda}_{\mathrm{LT}} \leq 0.4$. For $\bar{\lambda}_{\mathrm{LT}} \leq 0.2$, the full value of $M_{\mathrm{csm}}$ may be used. Furthermore, if $M_{\mathrm{csm}}<M_{\mathrm{pl}}$, then $\bar{\lambda}_{\mathrm{LT}}^{\mathrm{csm}}=0.2$ remains, but the transition should be from $M_{\mathrm{el}}$ rather than $M_{\mathrm{pl}}$ at $\bar{\lambda}_{\mathrm{LT}}=0.4$. These design expressions are illustrated in Fig. 22 for a typical range of values of $M_{\mathrm{csm}}$. 


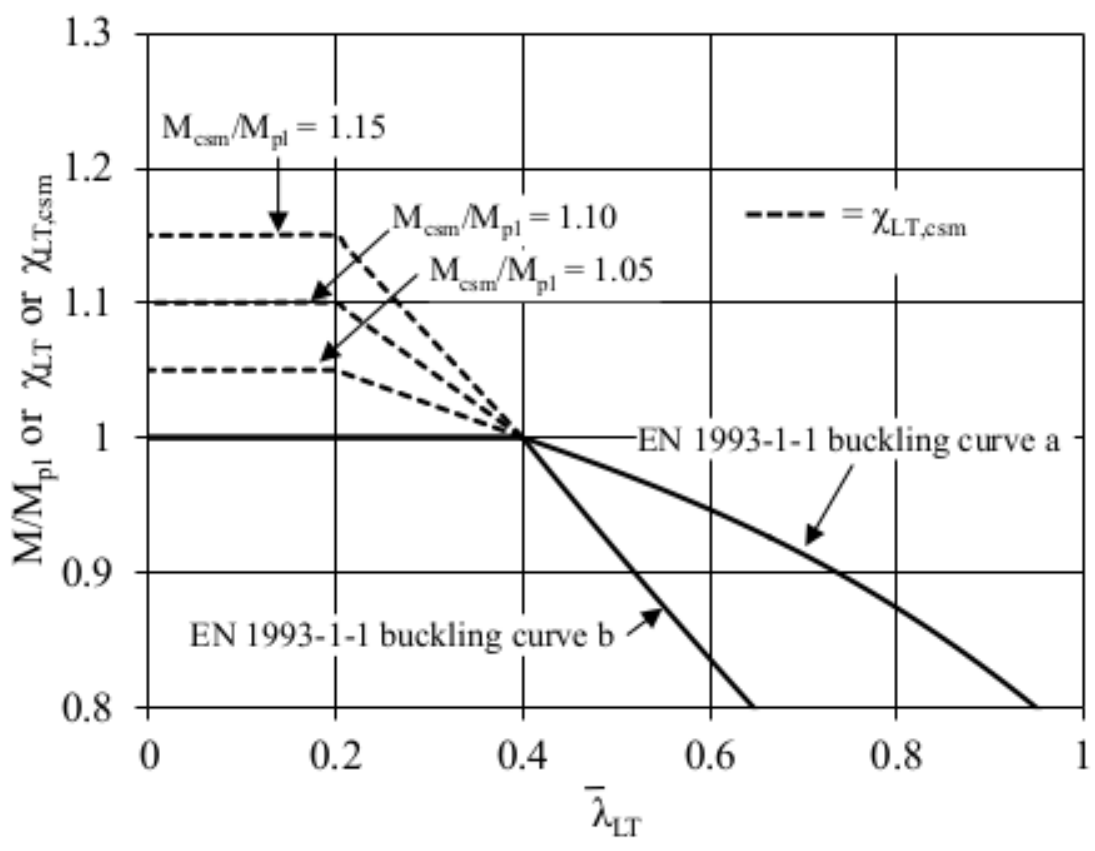

Figure 22: Illustration of the application of the factor $\chi_{\mathrm{LT}, \mathrm{csm}}$ for a typical range of values of $M_{\mathrm{csm}}$.

\section{Conclusions and design recommendations}

Using the insights obtained from an analytical model in conjunction with data generated either from tests performed in this study, collected from the literature, or from a numerical model, the lateral-torsional buckling instability implications of allowing for strain-hardening in the design of structural steel members have been considered.

A simplified analytical model was developed to investigate the influence of the key parameters of the CSM on the limiting values of $\bar{\lambda}_{\mathrm{LT}}$, where it was demonstrated that cross-section geometry was the most significant parameter. Using a simple methodology, a conservative relationship between $\bar{\lambda}_{\mathrm{LT}}$ and $M_{\mathrm{csm}}$, which is entirely based upon strain-hardening material properties, was reviewed and shown to be safe but conservative. Using additional data generated as part of an analytical and numerical study, as well as test data collected from the literature, a basic design approach was presented that incorporated a limiting CSM slenderness of $\bar{\lambda}_{\mathrm{LT}} \leq 0.2$ as well as a transition function from $M_{\mathrm{pl}}$ to $M_{\mathrm{csm}}$ via the factor 
$\chi_{\mathrm{LT}, \mathrm{csm}}$. 
[1] L. Gardner, The Continuous Strength Method, Proceedings of the Institution of Civil Engineers - Structures and Buildings 161 (3) (2008) 127-133.

[2] L. Gardner, F. Wang, A. Liew, The influence of strain hardening on the behaviour and design of steel structures, International Journal of Structural Stability and Dynamics $11(05)$ (2011) 855-875.

[3] C.A.S.E., Compression tests of stainless steel tubular columns, Tech. Rep. Investigation Report S770, University of Sydney Centre for Advanced Structural Engineering, 1990.

[4] R. Greiner, P. Kaim, Comparison of LT-buckling curves with test results, Tech. Rep. 23, ECCS TC 8, 2001.

[5] M. P. Byfield, D. A. Nethercot, An analysis of the true bending strength of steel beams, Proceedings of the Institution of Civil Engineers - Structures and Buildings 128 (2) (1998) 188-197.

[6] M. W. White, The lateral torsional buckling of yielded structural steel members, Ph.D. thesis, Lehigh University, 1956.

[7] G. C. Lee, A. T. Ferrara, T. V. Galambos, Experiments on braced wide-flange beams, Tech. Rep. 205H.6, Fritz Engineering Laboratory, 1963.

[8] J. Prasad, T. V. Galambos, The influence of adjacent spans on the rotation capacity of beams, Tech. Rep. 205H.12, Fritz Engineering Laboratory, 1963.

[9] Simulia, ABAQUS/Standard user's manual volumes I-III and ABAQUS CAE manual., Hibbit Karlsson, Sorensen Inc., Pawtucket, 2010.

[10] T. Chan, L. Gardner, Compressive resistance of hot-rolled elliptical hollow sections, Engineering Structures 30 (2008) 522-532.

[11] R. G. Dawson, A. C. Walker, Post-buckling of geometrically imperfect plates, Journal of the Structural Division (ASCE) ST1 (1972) 75-94. 
[12] L. Gardner, D. Nethercot, Numerical modeling of stainless steel structural components a consistent approach, Journal of Structural Engineering (ASCE) October (2004) 15861601.

[13] B. W. Young, Residual stresses in hot-rolled sections, Tech. Rep. CUED/C-Struct/TR.8, Unviersity of Cambridge Department of Engineering, 1971.

[14] D. A. Nethercot, Residual stresses and their influence upon the lateral buckling of rolled steel beams, The Structural Engineer 52 (1974) 89-96.

[15] T. V. Galambos, Inelastic lateral buckling of beams, Journal of the Stuctural Division (ASCE) 89 (ST 5) (1963) 217.

[16] N. S. Trahair, Flexural Torsional Buckling of Structures, Spon Press, 1993.

[17] F. Bleich, Buckling Strength of Metal Structures, McGraw-Hill, 1952.

[18] S. P. Timoshenko, J. Gere, Theory of Elastic Stability, McGraw-Hill, London, 2nd edn., 1961.

[19] L. Euler, Sur la force des colonnes, Memoires Academic Royale des Sciences et Belle Lettres 13 (1759) 309-18.

[20] B. Saint-Venant, Memoire sur la torsion des prismes, Memoires des Savants Etrangers XIV (1855) 233-560.

[21] L. Prandtl, Kippersheinungen, Ph.D. thesis, Munich, 1899.

[22] A. G. M. Michell, Elastic stability of long beams under transverse forces, Philosophical Magazine 1 (48) (1899) 298-309.

[23] S. P. Timoshenko, The Collected Papers of Stephen P. Timoshenko, chap. Einige Stabilitaetsprobleme der Elastizitaetstheorie, McGrawHill, 1-50, 1953.

[24] S. P. Timoshenko, The Collected Papers of Stephen P. Timoshenko, chap. Sur la stabilite des systemes elastiques, McGrawHill, 92-224, 1953. 
[25] H. Wagner, Verdrehung und Knickung von offenen Profilen (Torsion and buckling of open sections), Tech. Rep. TM 784, NACA, 1936.

[26] A. R. Flint, The stability and strength of stocky beams, Journal of the Mechanics and Physics of Solids 1 (1953) $90-102$.

[27] B. G. Neal, Lateral instability of yielded mild steel beams of rectangular cross-section, Philosophical Transactions of the Royal Society, Series A 242 (1950) 197.

[28] J. L. Morrison, W. M. Shepherd, An experimental investigation of plastic stress-strain relations, Journal of the Institution of Mechanical Engineers 163 (1950) 1 - 17.

[29] D. A. Nethercot, K. C. Rockey, The lateral buckling of beams having discrete intermediate restraints, The Structural Engineer 10 (1972) 391-403.

[30] SCI, Steel building design: Design data, The Steel Construction Institute, 2013.

[31] N. S. Trahair, Stability and Ductility of Steel Structures, chap. Multiple Design Curves for Beam Lateral Buckling, Pergamon, 13-27, 1998. 